\title{
EDUCACIÓN VIAL DURANTE EL FRANQUISMO. MEMORIA DE LOS PRIMEROS PARQUES INFANTILES DE TRÁFICO EN MALLORCA (1962-1975)
}

\author{
Road Safety Education during the Franco Regime: the first \\ Children's Traffic Parks in Majorca (1962-1975)
}

\author{
Gabriel Barceló-Bauzà ${ }^{\beta}$ y Llorenç Gelabert-Gual $\gamma$ \\ Fecha de recepción: 28/06/2018 • Fecha de aceptación: 03/09/2018
}

Resumen. La coyuntura de cierto crecimiento económico que se vislumbraba en España entre finales de los años cincuenta y principios de los sesenta del siglo pasado ejerció, en mayor o menor medida, influjo en el ámbito educativo. Prueba de ello fue la introducción en la escuela de nuevos contenidos curriculares como la educación vial, que empezó a ocupar un espacio en el horario escolar. Este artículo presenta una aproximación a los parques infantiles de tráfico, unos espacios creados con la intención de inculcar hábitos de seguridad vial a través de prácticas reales y que resultaban complementarias a la formación teórica que se impartía en el aula. Los niños haciendo prácticas en el rol de conductores de vehículos, peatones o guardias de tráfico fueron algunas de las actividades más características. En esta ocasión nos centramos en los parques creados en Mallorca, un territorio insular que en el último tercio del siglo pasado soportó un aumento significativo del tráfico rodado, debido principalmente al incremento poblacional fruto del boom turístico y de una coyuntura de fuerte expansión económica. Para elaborar un inventario de los parques

\footnotetext{
a Artículo realizado en el marco del proyecto Cultura y prácticas escolares en el siglo XX (EDU201782485-P), financiado por el Ministerio de Ciencia, Innovación y Universidades (MCIU), la Agencia Estatal de Investigación (AEI) y el Fondo Europeo de Desarrollo Regional (FEDER, UE).

Agradecimientos: Violeta Manso, Antoni Femenia, Elvira Oliver, Antoni Sureda, Pedro J. Barceló, Joan Payeras, Bartomeu Alomar, Joan Llabrés y Bartomeu A. Pou.

в Departamento de Pedagogía y Didácticas Específicas, Facultad de Educación, Universitat de les Illes Balears (GEDHE/IRIE). Ed. Guillem Cifre de Colonya, Ctra. de Valldemossa, km 7.5, 07122 Palma, España. gabriel.barcelo@uib.cat (1D http://orcid.org/0000-0001-8997-8870

$\checkmark$ Departamento de Pedagogía y Didácticas Específicas. Facultad de Educación, Universitat de les Illes Balears (GEDHE/IRIE). Ed. Guillem Cifre de Colonya, Ctra. de Valldemossa, km 7.5, 07122 Palma, España. llorens.gelabert@uib.es (D) https://orcid.org/0000-0003-1669-1080
}

Cómo citar este artículo: Barceló-Bauzà, Gabriel y Llorenç Gelabert-Gual. «Educación vial durante el franquismo. Memoria de los primeros parques infantiles de tráfico en Mallorca (19621975)». Historia y Memoria de la Educación 10 (2019): 345-379 
existentes y realizar el análisis de su legado y aportaciones, hemos accedido a toda una serie de fuentes - escritas, orales y gráficas- que nos han permitido aportar datos e informaciones del contexto en que fueron creados, de las personas encargadas de impulsarlos, así como de la importancia de su implementación en los auspicios de un nuevo paradigma educativo.

Palabras clave: Escuela primaria; Educación vial; Parques infantiles de tráfico; Franquismo; Mallorca.

Abstract. The situation brought about by economic growth that was visible in Spain between the end of the fifties and the beginning of the sixties of the last century exerted, to a greater or lesser extent, an influence on education. Proof of this was the introduction into the school of new curricular contents such as road education, which began to occupy its own space in school hours. This article presents an introduction to the children's traffic parks that were created to instil road safety habits through real practice and which supplemented the theoretical training given in classrooms. Typical activities would include children engaged in role-playing, being drivers, pedestrians or traffic wardens. This article focuses on the parks in Majorca - an island te rritory that saw a major increase in road traffic in the last thirty years of the 20th century, mainly due to population growth resulting from the tourism boom and to a highgrowth economic outlook. In order to put together an inventory of the existing parks and to undertake an analysis of their legacy and contributions, we have used a series of sources (written, oral and illustrated) that has enabled us to provide empirical data on the context in which they were created, on those responsible for promoting them, and on the importance of their introduction under the auspices of a new education programme.

Keywords: Primary school; Road safety education; Children's traffic parks; Franco regime; Majorca.

\section{INTRODUCCIÓN}

La incorporación del vehículo en nuestra sociedad ha obligado, tanto a usuarios de la vía pública como a las instituciones competentes, a adquirir un compromiso firme en cuanto a su regulación y conciliación. Este hecho se acentuó con el fenómeno del boom automovilístico acaecido en España en la década de los sesenta del siglo pasado, que vino acompañado de un aumento creciente del número de siniestros con víctimas mortales (tablas 1 y 2). ${ }^{1}$ En este contexto se empezaron a tomar nuevas

\footnotetext{
1 Para una mayor información sobre las cifras relativas a la siniestralidad vial en España puede consultarse el Anuario Estadístico General. Dicha publicación, elaborada de forma ininterrumpida
} 
medidas y a plantearse nuevos retos dirigidos a la concienciación ciudadana, aunque no únicamente en términos legales y de cumplimiento de las normas de circulación, sino incluyendo nuevos conceptos más relacionados con la educación en valores cívicos.

Tabla 1

\begin{tabular}{|c|c|c|c|}
\hline \multirow{2}{*}{ Año } & \multicolumn{3}{|c|}{ Cifras de accidentes de tráfico (1960-1975) } \\
\hline & Carretera & Zona urbana & Total \\
\hline 1960 & 17.866 & 41.038 & 58.904 \\
\hline 1961 & 21.131 & 43.235 & 64.366 \\
\hline 1962 & 23.519 & 27.968 & 51.487 \\
\hline 1963 & 25.231 & 28.903 & 54.134 \\
\hline 1964 & 29.228 & 32.048 & 61.276 \\
\hline 1965 & 32.347 & 42.127 & 74.474 \\
\hline 1966 & 32.449 & 41.350 & 73.799 \\
\hline 1967 & 33.215 & 44.439 & 77.654 \\
\hline 1968 & 34.565 & 44.929 & 79.494 \\
\hline 1969 & 35.823 & 45.959 & 81.782 \\
\hline 1970 & 37.036 & 47.625 & 84.661 \\
\hline 1971 & 37.127 & 47.454 & 84.581 \\
\hline 1972 & 42.713 & 50.314 & 93.027 \\
\hline 1973 & 45.804 & 53.086 & 98.890 \\
\hline 1974 & 42.883 & 49.207 & 92.090 \\
\hline 1975 & 44.035 & 48.700 & 92.735 \\
\hline
\end{tabular}

Fuente: Anuario Estadístico General (Jefatura Central de Tráfico. Dirección General de Tráfico). Elaboración propia.

por la Dirección General de Tráfico (DGT) — antes Jefatura Central de Tráfico (JCT)_, permite ver, entre otros aspectos, la evolución del número de accidentes y víctimas mortales acaecidos en España desde el año 1960 hasta la actualidad. Para una mayor información, véase: http://www.dgt.es/es/seguridad-vial/estadisticas-e-indicadores/publicaciones/anuario-estadistico-general/index-paginacion-006.shtml (consultado el 11-02-2018). 
Tabla 2

\begin{tabular}{|c|c|c|c|}
\hline \multirow{2}{*}{ Año } & \multicolumn{3}{|c|}{ Cifras de víctimas mortales en accidentes de tráfico (1960-1975) } \\
\hline & Carretera & Zona urbana & Total \\
\hline 1960 & 1.300 & 460 & 1.760 \\
\hline 1961 & 1.335 & 473 & 1.808 \\
\hline 1962 & 1.603 & 395 & 1.998 \\
\hline 1963 & 1.785 & 445 & 2.230 \\
\hline 1964 & 1.997 & 491 & 2.488 \\
\hline 1965 & 2.237 & 565 & 2.802 \\
\hline 1966 & 2.383 & 839 & 3.222 \\
\hline 1967 & 2.749 & 886 & 3.635 \\
\hline 1968 & 2.865 & 938 & 3.803 \\
\hline 1969 & 3.132 & 819 & 3.951 \\
\hline 1970 & 3.296 & 901 & 4.197 \\
\hline 1971 & 3.430 & 817 & 4.247 \\
\hline 1972 & 3.588 & 865 & 4.453 \\
\hline 1973 & 3.823 & 941 & 4.764 \\
\hline 1974 & 3.433 & 886 & 4.319 \\
\hline 1975 & 3.714 & 773 & 4.487 \\
\hline
\end{tabular}

Fuente: Anuario Estadístico General (Jefatura Central de Tráfico. Dirección General de Tráfico). Elaboración propia.

Las legislaciones evolucionaron y han seguido evolucionando de forma paralela al grado de conciencia que ha ido adquiriendo la sociedad en materia de seguridad vial. Ya durante el periodo histórico de la Segunda República se abrió por primera vez el debate sobre la importancia de la educación vial y su introducción en la escuela. No obstante, su implantación no se llevó a cabo hasta la década de los sesenta, en plena dictadura franquista, a partir de la creación, entre otras medidas, de parques infantiles de tráfico. Estos parques, constituidos como espacios educativos en los cuales se ponían en práctica los conocimientos adquiridos, se 
convirtieron en una herramienta pedagógica de gran utilidad y aceptación en todo el territorio español y gozaron de amplia difusión por parte de los medios de entonces, tanto aquellos más directamente controlados por el régimen como por publicaciones de ámbito local. Los niños haciendo prácticas como peatones, conductores o guardias de tráfico, en unos años en que el boom automovilístico cambió radicalmente el aspecto y la seguridad de las calles y carreteras, llamó la atención de la sociedad en general. Todo ello sirvió para proyectar una imagen más moderna de España y de su educación.

Asimismo, la difusión de estos parques facilitó la creación de iniciativas de carácter estatal como exposiciones de trabajos escolares relacionadas con la educación vial o los populares Campeonatos Nacionales de Parques Infantiles de Tráfico. Precisamente, a través de este estudio, dejamos constancia de los parques que se crearon en Mallorca en la década de los sesenta y setenta del siglo XX, analizando además su aportación y legado. A través de testimonios orales, visuales y escritos, hemos llegado a recopilar información sobre los cinco parques creados durante ese periodo. Es destacable, pues, su grado de implementación en un territorio insular como es la isla de Mallorca.

\section{EDUCACIÓN VIAL Y LEGISLACIÓN}

El concepto de educación vial ha ido variando en las últimas décadas en función de los distintos contextos sociales y políticos que han tenido lugar en España; ${ }^{2}$ desde aquellos exclusivamente centrados en las directrices y normativas de circulación, hasta concepciones más inclusivas que atienden a aspectos cívicos, convivenciales o medioambientales. El Consejo de Europa y la Conferencia Europea de Ministros de Transporte han compartido la realización de las Conferencias Mixtas, celebradas en París (1963) y Viena (1971), con el fin de unificar criterios en favor de la educación vial y la seguridad en los distintos países miembros de Europa. En estos encuentros, celebrados en un contexto de expansivo aumento del uso del automóvil y del número de víctimas mortales como consecuencia de accidentes de tráfico, se establecieron líneas de actuación enfocadas a la dimensión educativa de la seguridad vial y a la preparación de futuros

\footnotetext{
${ }^{2}$ María Paz Trillo Miravalles, «Evolución legislativa de la educación vial en España: nuevos retos para educadores e instituciones», Ensaio: Avaliação 22, no. 82 (2014): 131-148.
} 
conductores. Bien es cierto, que en España el término educación vial no apareció mencionado explícitamente por parte de la Jefatura Central de Tráfico (JCT) hasta el año 1962.

En una concepción más actualizada, tal y como señala Violeta Manso, la educación vial puede concebirse como aquella acción educativa que ha sido diseñada, implementada y evaluada con la intención de facilitar los aprendizajes cognitivos y emocionales que permiten a los usuarios de las vías actuar de forma responsable, especialmente con aquellos más vulnerables como es el caso de los peatones o ciclistas de poca edad. ${ }^{3}$ En este sentido, la educación vial se convierte en una estrategia de carácter preventivo que ayuda a fomentar una movilidad más sostenible, segura, eficiente y ecológica. Eugenio Ocio, del Centro de Investigación y Documentación Educativa, define la educación vial como un elemento imprescindible en la formación de los ciudadanos que favorece las relaciones humanas en los espacios públicos, fomentando valores como la convivencia, la tolerancia, la solidaridad, la responsabilidad y el respeto. ${ }^{4}$ Murga enfatiza el valor de la educación vial como recurso para paliar problemáticas sociales, medioambientales y económicas. ${ }^{5}$ Sobre su implementación en la escuela, Miguel Ángel Zabalza propone una formación útil y actualizada presente en todas las etapas escolares y adaptada a todos los sujetos y dimensiones de la vida. ${ }^{6}$

En cuanto a la introducción de la educación vial en los centros educativos, cabe decir que no aparece referencia alguna hasta la aprobación del Código de Circulación del año 1934, durante la Segunda República. En su artículo séptimo establece como obligatoria la enseñanza de las normas de tráfico en los centros escolares:

\footnotetext{
3 Violeta Manso Pérez, «Educación Vial para la Educación Secundaria Obligatoria», en Innovar en las aulas. Modelos y experiencias de innovación educativa en el Máster de Profesorado de Educación Secundaria, Bachillerato, Formación Profesional y Enseñanza de Idioma, ed. Carmen López Esteban (Salamanca: Ediciones Universidad de Salamanca, 2018), 139-156.

${ }^{4}$ Eugenió Ocio Simó, «La Educación vial en España: marco histórico legal», en Educación vial, seguridad vial, ed. Carmen Jiménez Fernández (Barcelona: Editorial Davinci, 2010), 143-161.

5 María Ángeles Murga Menoyo, «La movilidad sostenible: un objetivo de la educación vial en el contexto europeo», en Educación vial, seguridad vial, ed. Carmen Jiménez Fernández (Barcelona: Editorial Davinci, 2010), 65-91.

' Miguel Ángel Zabalza Beraza, «La educación vial en el marco de una formación por competencia», en Educación vial, seguridad vial, ed. Carmen Jiménez Fernández (Barcelona: Editorial Davinci, 2010), 162-184.
} 
El profesorado de todas las Escuelas y Colegios, tanto oficiales como particulares, está obligado a enseñar a sus alumnos las reglas generales de la circulación y la conveniencia de su perfecta observancia; advirtiéndoles de los grandes peligros a que se exponen al jugar en las calzadas de las vías públicas, salir atropelladamente de los Centros docentes, subir a la parte posterior de los vehículos y topes de los tranvías, etcétera El Ministerio de Instrucción pública dictará las oportunas disposiciones que aseguren la conveniente vigilancia del cumplimiento de este precepto. ${ }^{7}$

Con la aprobación de este nuevo código de circulación se hacía evidente la apertura, por parte del gobierno republicano, a nuevos paradigmas y concepciones educativas, dirigidas a la formación en valores y cívica de sus ciudadanos. Esta declaración de intenciones, empero, jamás tuvo una aplicación real en las aulas. El fenómeno del tráfico en las calles y carreteras españolas no constituía entonces un asunto que preocupara demasiado a las instituciones competentes. Si bien en países como Francia o Alemania el gasto en materia de problemas derivados del tráfico había aumentado considerablemente, en España se contaba todavía con un parque automovilístico muy reducido. No obstante, Manso y Castaño consideran que se establecieron unas bases educativas bien cimentadas de cara a aportaciones futuras. ${ }^{8}$ Esta nueva legislación, además, se adhería a algunos textos ya aprobados en el ámbito internacional, que pretendían unificar normativas respecto al tráfico urbano y todos sus agentes implicados.

Con todo, la inclusión efectiva de la educación vial en los centros escolares no tuvo lugar hasta la década de los sesenta. La Orden de 29 de abril de 1961 del Ministerio de Educación Nacional, ${ }^{9}$ establecía la obligatoriedad de la enseñanza de las normas de seguridad vial reguladas por el código de circulación entonces vigente. Esta normativa estableció una hora de clase teórica al mes y la inclusión de actividades o juegos prácticos

\footnotetext{
7 «Código de la Circulación», Gaceta de Madrid no. 269 (26 de septiembre de 1934): 2635.

8 Violeta Manso Pérez y Manuel Castaño Pardo, Educación para la seguridad vial (Madrid: Grupo Anaya, 1995), 41.

9 «Orden de 29 de abril de 1961 relativa a la obligatoriedad de la enseñanza de las reglas de Seguridad en la circulación por las vías públicas reguladas en el Código de Circulación vigente, en todas las Escuelas Primarias», Boletín Oficial del Estado (BOE) no. 108 (6 de mayo de 1961): 6875-6876.
} 
vinculados al área de educación física. A través de la Resolución de 1 de septiembre de 1962, que emanaba de la Orden anterior, se publicaron las normas didácticas y los temas referidos a formación vial en las escuelas nacionales de enseñanza primaria - la elaboración de dichos programas corrió a cargo del Centro de Documentación y Orientación Didáctica de Enseñanza Primaria (CEDODEP)—. ${ }^{10}$ Se establecieron tres niveles de enseñanza distribuidos entre alumnos de seis a quince años, a partir de ejes temáticos como: hábitos de observación; hábitos psicomotores; hábitos de circulación correcta; hábitos de responder prontamente a señales visuales y sonoras; hábitos de dominio y control emotivo; nociones sobre la calzada, nociones sobre vehículos frecuentes; normas de circulación del peatón; conocimiento de las señales más necesarias para el peatón; hábitos de cortesía y buena educación; recomendaciones y consejos dictados por la prudencia; hábitos de observación: distancias, tiempos, velocidades; conocimiento de la bicicleta; hábitos y normas de conducción de la bicicleta; imprudencias que deben evitarse en la conducción nocturna; normas de conducción de animales y vehículos agrícolas; conocimiento de señales verticales, horizontales y luminosas; desarrollo de la capacidad de autocontrol y del sentido de la circulación; conocimiento de señales de peligro, prohibición y obligación; el guardia de circulación; los semáforos; los pasos a nivel; vehículos y el comportamiento; conductores, edad y comportamiento; las sanciones; responsabilidad de los conductores y propietarios de vehículos; y, finalmente, temas relacionados con los seguros. Pocos años después, a través de la Orden de 11 de enero de 1967,11 se regulaba por primera vez la creación y reglamentación de los parques infantiles de tráfico. A esta normativa le siguieron las aprobadas en 1989, 1992 y 1994, que dieron como resultado los parques existentes en la actualidad. ${ }^{12}$ Éstos se

\footnotetext{
10 «Resolución de la Dirección General de Enseñanza Primaria por la que se hacen públicas las normas didácticas y los temas para la enseñanza de la circulación en las Escuelas Nacionales de enseñanza primaria, dando cumplimiento a lo dispuesto en el número 4 de la Orden de 29 de abril de 1961», BOE, no. 233 (28 de septiembre de 1962):13719-13720.

11 «Orden de 11 de enero de 1967 por la que se establecen las bases por las que han de regirse la creación y reglamentación de Parques Infantiles de Tráfico», BOE no. 35 (10 de febrero de 1967): 1808-1809.

12 «Orden de 31 de enero de 1989 por la que se regula la creación, funcionamiento y reglamentación de los Parques Infantiles de Tráfico», BOE no. 56 (7 de marzo de 1989): 6385; «Resolución de 15 de septiembre de 1992, de la Dirección General de Tráfico, por la que se desarrolla la Orden del Ministerio del Interior de 31 de enero de 1989, por la que se reguló la creación, funcionamiento y reglamentación de los Parques Infantiles de Tráfico», BOE no. 289 (2 de diciembre de 1992): 40765-40766; «Resolución de 28 de octubre de 1994, de la Dirección General de Tráfico, por la que se modifica la de 15 de septiembre de 1992, que desarrolla la Orden del Ministerio del Interior de 31 de enero
} 
constituyeron como espacios educativos en los cuales los alumnos podían poner en práctica los conocimientos teóricos trabajados en el aula a partir de los bloques temáticos mencionados anteriormente. ${ }^{13}$

Cabe destacar, sin embargo, que el profesorado de los centros educativos no contaba entonces con una formación específica en materia de educación y seguridad vial. Por ello, este tipo de enseñanza no se dio, ni muchos menos, de forma generalizada en todo el territorio estatal. Merece especial mención, en este aspecto, la labor educativa vinculada a los parques infantiles de tráfico desempeñada por parte de policías locales de muchas localidades del territorio español. En este punto, también debemos destacar que la JCT — creada en el año 1959 y adscrita al Ministerio de Gobernación- $-{ }^{14}$ venía impulsando líneas de actuación dirigidas a la mejora de la educación vial en distintos ámbitos — campañas estatales de concienciación, elaboración de materiales didácticos, formación de profesores de autoescuela; y, posteriormente, concursos de dibujo o Campeonatos Nacionales de Parques Infantiles de Tráfico-, supliendo así la inacción por parte de las instituciones educativas competentes. No obstante, la normalización de la educación vial en los centros escolares no se produjo hasta la aprobación de los Programas Renovados en el año 1981.

\section{LOS PARQUES INFANTILES DE TRÁFICO, UNA HERRAMIENTA INNOVADORA}

Los primeros parques en Mallorca, así como en el resto de España, surgieron a raíz de la creación de la JCT y de la aprobación posterior de la Orden de 29 de abril de 1961, que obligaba a enseñar en todas las escuelas las normas del código de circulación. A través de esta nueva normativa se estipuló una hora de enseñanzas teóricas al mes y diferentes modalidades de clases prácticas en función de la edad de los escolares. Los parques de tráfico, además de ser unos espacios creados para la formación del ciudadano urbano en su proceso de adaptación a un entorno

\footnotetext{
de 1989, por la que se reguló la creación, funcionamiento y reglamentación de los Parques Infantiles de Tráfico», BOE no. 271 (12 de noviembre de 1994): 34946.

13 Manso y Castaño, Educación para la seguridad vial, 58-71.

14 «Ley 47/1959, de 30 de julio, sobre regulación de la competencia en materia de tráfico en el territorio nacional», BOE no. 182 (31 de julio de 1959): 10371-10372.
} 
cada vez más motorizado, fueron el principal recurso para la formación práctica de los alumnos en el ámbito de la educación vial.

Violeta Manso, en su tesis doctoral sobre la educación vial en España, define estos parques como la reproducción a escala infantil de los elementos que presenta la circulación: calzada, aceras, peatones, vehículos a motor, señales, etcétera. ${ }^{15}$ Desde sus inicios, y bajo los auspicios de la JCT, se convirtieron en una atractiva herramienta didáctica para los alumnos, a partir de la cual podían efectuar prácticas desempeñando distintos roles - conductores de bicicletas, ciclomotores, karts, guardias de tráfico o peatones- y viviendo situaciones en primera persona muy cercanas a la realidad del medio urbano. La orden del Ministerio de Gobernación del año 1967, que regulaba su creación, surgió a raíz de la proliferación de los mismos por todo el territorio español. Constituyeron, sin duda alguna, un novedoso recurso pedagógico con una amplia repercusión mediática en la prensa local y estatal de entonces.

El primer parque móvil se instaló en diciembre del año 1961 en el Palacio de Deportes de Madrid, con gran éxito de acogida. ${ }^{16}$ Se crearon, inicialmente, cinco parques itinerantes en doce poblaciones españolas, abasteciendo a un colectivo cercano a los 35.000 alumnos. En el año 1965 se contaba ya con parques instalados en 19 ciudades o municipios españoles que abastecían a un colectivo de 50.000 alumnos. Ante la imposibilidad de llegar a la totalidad del alumnado español, desde la JCT se distribuyeron materiales didácticos a maestros de todo el Estado, realizándose también concursos y campañas de propaganda y concienciación. Este mismo año tendría lugar el Primer Campeonato Nacional de Parques Infantiles de Tráfico. ${ }^{17}$

En el año 1966 se inauguraron tres instalaciones fijas en Castellón, Ponferrada y Gijón. Se abastecía ya entonces a un total de 65.000

\footnotetext{
15 Violeta Manso Pérez, «La educación vial en España. Aspectos históricos-comparados y proyección social» (Tesis doctoral, Universidad de Salamanca, 1993), 56.

16 Anónimo, «Un aspecto del Parque Infantil de Tráfico, instalado por la Jefatura Central en el Palacio de Deportes con motivo de la inauguración del I Salón de la Infancia», $A B C$ (Madrid), 24 de diciembre de 1961.

17 Sobre la celebración del I Campeonato Nacional de Parques Infantiles de Tráfico en 1965 puede consultarse: NO-DO número $1.168 \mathrm{C}$ (minuto 1:42 a 3:14) de 24 de mayo de 1965. http://www.rtve.es/ filmoteca/no-do/not-1168/1475998/ (consultado el 11-02-2018).
} 
escolares. Paralelamente, se llevaron a cabo otro tipo de acciones como la primera Campaña del Peatón y el Primer Concurso Nacional de Dibujos Infantiles sobre Tráfico, celebrados en Girona y Ripoll, o campañas de divulgación, incorporando 500.000 guías del peatón y materiales didácticos, como manuales o películas. Aparecieron también, este mismo año, las primeras Campañas sobre Seguridad Vial dirigidas a la población adulta, que incluían boletines informativos, artículos en periódicos de tirada nacional o spots televisivos. ${ }^{18}$

En los años posteriores se siguieron creando nuevos parques, acompañados de nuevas iniciativas dirigidas a la concienciación y formación de los escolares, así como la reedición de materiales didácticos diseñados en años anteriores. En el año 1967 se inauguraron parques en Astorga, Palencia y Andorra. Al año siguiente, además de incrementarse la cifra de parques, se adquirieron, por parte de la JCT, nuevas películas que trataban temáticas relacionadas con la seguridad vial y pautas de conducta por parte de usuarios de la vía pública. En 1969 se crean parques en Ferrol, Escoriaza, Sabero, Logroño, Felanitx, Gilet, Toledo, Almería y Jaén, y en el año 1971 ya consta la existencia de un total de 50 parques distribuidos por todo el Estado. ${ }^{19}$

Durante la década de los setenta se siguieron creando nuevas instalaciones y se llevaron a cabo nuevas acciones como cursillos infantiles de educación vial. Destaca la creación de las Cátedras Ambulantes de Tráfico en Educación Vial, encargadas de realizar acciones educativas sobre educación y seguridad vial en diferentes localidades, impartiendo charlas, realizando murales o instalando parques de carácter móvil. ${ }^{20}$ En este sentido, también debemos reseñar que durante la etapa de Carlos $\mathrm{Mu}$ ñoz-Repiso — director general de la DGT entre 1971 y 1976 — se utilizaron las representaciones teatrales como instrumento para la concienciación en materia de educación y seguridad vial. Se escribieron un total de cuatro obras que se representaron a lo largo de toda la geografía española. ${ }^{21}$

\footnotetext{
18 Manso, «La educación vial en España», 65.

19 Manso, «La educación vial en España», 67-69.

20 Manso, «La educación vial en España», 76-80.

21 Javier Coromina Doisy, Cincuentenario de la DGT: 1959-2009 (Madrid: Dirección General de Tráfico. Ministerio del Interior, 2009), 167.
} 


\section{LOS PRIMEROS PARQUES INFANTILES DE TRÁFICO EN MALLORCA (1962-1975)}

En este estudio nos centramos en los parques infantiles de tráfico creados en Mallorca, territorio que precisamente entre los años sesenta y setenta del siglo pasado vivió un progresivo aumento de la presión demográfica debido a la incesante llegada de turistas y nuevos trabajadores relacionados con este sector. Cabe añadir que este aumento del parque de vehículos a motor, vinculado a un marcado crecimiento poblacional, tuvo lugar también en otras regiones del Estado, en especial en las zonas costeras con un alto impacto del fenómeno turístico.

Centrándonos ya en el caso de Mallorca, es preciso mencionar la creación, entre los años 1962 y 1975, de un total de cinco parques: Palma (1962), Campos (1963), sa Pobla (1965), Felanitx (1969) y Manacor (1974). Este número de parques situó a Mallorca como la región de España con un mayor porcentaje de parques por habitante, tal y como afirmaba Vicente Carredano — jefe de relaciones públicas de la DGT_ en 1975.22 De todos ellos el parque de Palma fue el único parque móvil. Una vez expuesta la relación de parques creados en la isla, pasaremos a sintetizar como fueron sus inicios, quiénes fueron sus impulsores e incidiremos especialmente en las actividades que se desarrollaron.

\section{Parque Infantil de Tráfico de Palma (1962)}

El parque móvil de Palma se abrió al público el 14 de mayo de 1962 y fue uno de los primeros creados en España. ${ }^{23}$ A su inauguración asistieron alumnos de los centros escolares de la ciudad y diferentes autoridades como el gobernador civil, Plácido Álvarez-Buylla, el presidente de la Diputación Provincial, Rafael Villalonga, el alcalde de Palma, Juan Massanet, o el jefe provincial de Tráfico, Tomás Sastre (imagen 1).

\footnotetext{
22 Juan Payeras, «Vicente Carredano Gallo, jefe de relaciones públicas de la Dirección General de Tráfico. "Los parques tienden a educar al niño" », Diario de Mallorca, 4 de mayo de 1975.

${ }_{23}$ Anónimo, «Creación del Parque Infantil», Última Hora, 14 de mayo de 1962; Anónimo, «El Parque Infantil de Tráfico. Fue inaugurado ayer por nuestras autoridades. Es el primero en su clase que instala la Jefatura Central de Tráfico en España», Baleares, 15 de mayo de 1962; Anónimo, «Inauguración del Parque Infantil de Circulación. Una obra modélica instalada en el glacis de Santa Catalina», Diario de Mallorca, 15 de mayo de 1962.
} 


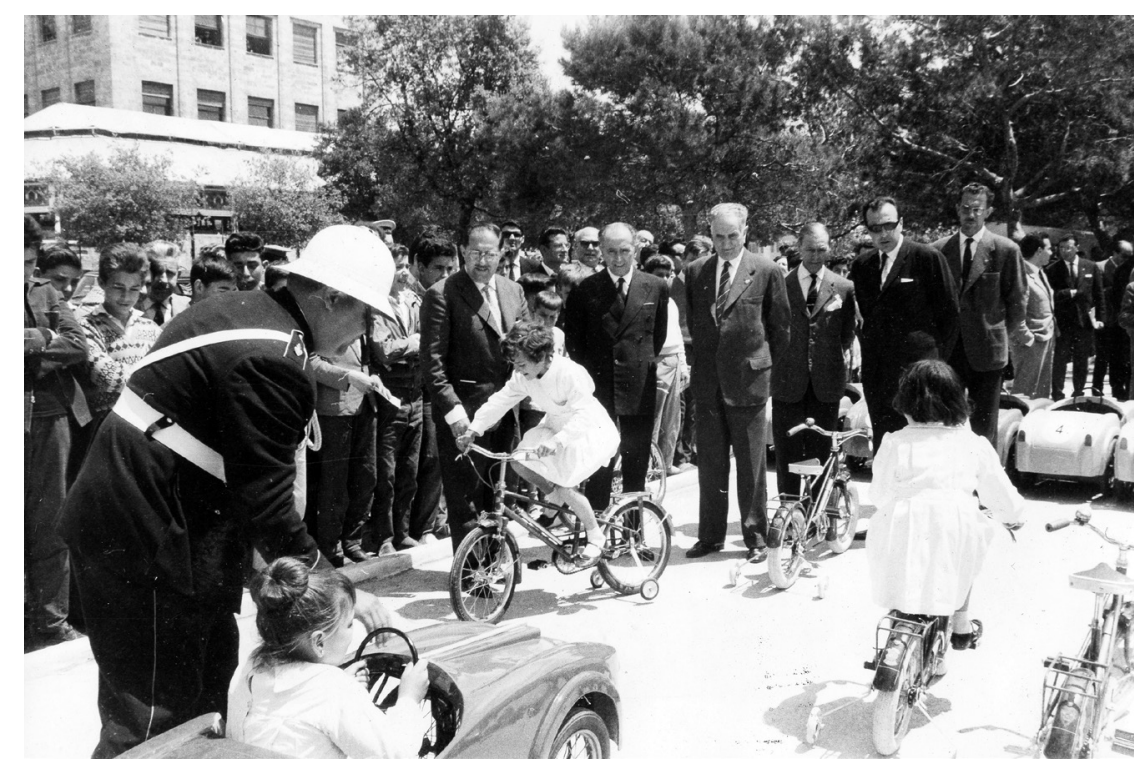

Imagen 1. Inauguración del Parque Infantil de Tráfico de Palma, jardines de sa Feixina (1962). Arxiu Municipal de Palma. Fons d'imatges. Autor: Castell.

Este primer parque de circulación se ubicó frente al grupo escolar Jaime I, concretamente en los jardines de sa Feixina. También colaboraron la JCT, que aportó distintos materiales — coches a pedal, bicicletas, etcétera-, así como la firma comercial Embotelladora Balear que proporcionó diferentes señalizaciones y la valla circundante que lo rodeaba. ${ }^{24}$ Durante las visitas los escolares realizaban prácticas de circulación por los cruces, vías, rotondas y plazas que había repartidos por todo el trazado respetando las señalizaciones —semáforos, direcciones prohibidas, carteles de zona escolar, etcétera-. Todo ello bajo la atenta supervisión de la Policía Municipal de Palma (imagen 2). ${ }^{25}$ Además del trazado, el parque contaba con unas tiendas de campaña anexas instaladas por miembros de la Organización Juvenil Española (OJE). En ellas se colocó un cuadro eléctrico de señalizaciones elaborado por

\footnotetext{
${ }^{24}$ Anónimo, «Inauguración del Parque Infantil de Circulación».

25 Para un mayor conocimiento de las actividades realizadas por la Policía Municipal de Palma puede consultarse la obra: Antoni Gorrias Durán, Miquel Ramis Serra y Arnau Tugores Ramis, 150 anys de la Policia Municipal: 1852-2002 (Palma: Ayuntamiento de Palma, 2002).
} 
alumnos de la Escuela de Maestría Industrial. ${ }^{26}$ Este cuadro sirvió para que los niños recordasen, con la ayuda de un monitor, qué significado tenían cada una de las señales que se encontraban a lo largo del recorrido (imagen 3). Esta primera experiencia estuvo en funcionamiento entre los días 14 y 25 de mayo de 1962. Tal y como explicaba la prensa de la época:

Los cochecitos y bicicletas pertenecientes a la Jefatura Central de Tráfico permanecerán en Palma durante varios días. Es propósito de la Jefatura Provincial contar para muy en breve con una flota propia que permita la continuidad de las instalaciones que quedaban inauguradas. ${ }^{27}$



Imagen 2. Prácticas de circulación en el parque de tráfico de Palma, jardines de sa Feixina (1962). Arxiu Municipal de Palma. Fons d'imatges.

Autor: Castell.

\footnotetext{
${ }^{26}$ Anónimo, «Mañana será inaugurado el Parque Infantil de Tráfico. Mientras juegan, los niños aprenderán las normas de circulación», Baleares, 13 de mayo de 1962.

${ }_{27}$ Anónimo, «El Parque Infantil de Tráfico», 4.
} 


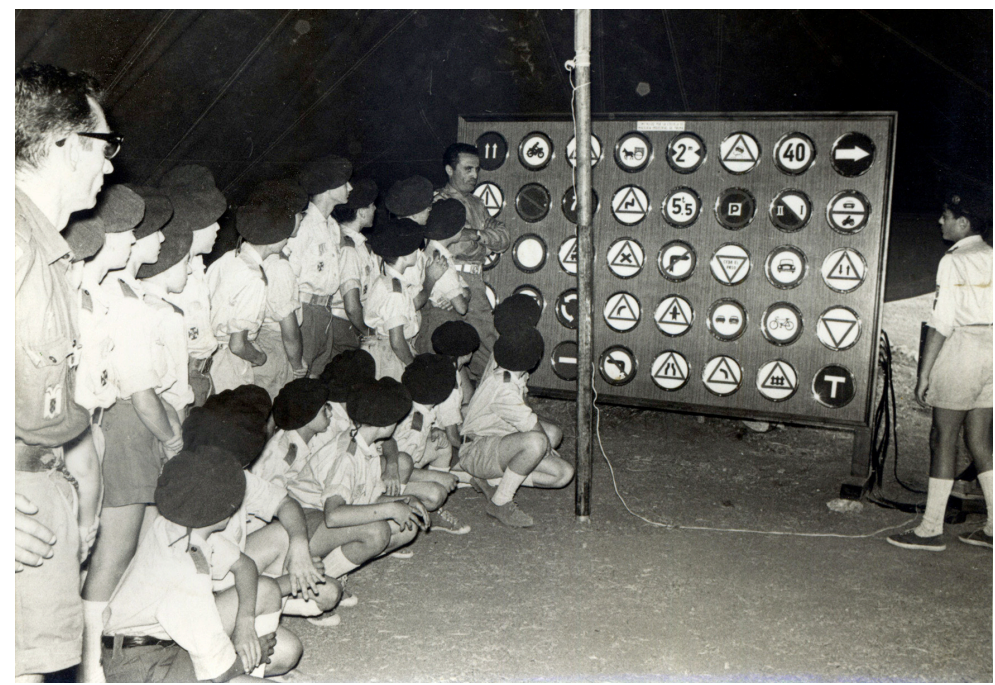

Imagen 3. Miembros de la Organización Juvenil Española (delegación de Palma) junto al cuadro eléctrico de señalizaciones (1962). Imagen cedida por Antoni Femenia. Autor: desconocido.

A pesar de la escasez inicial de recursos, el parque se siguió instalando, hasta 1965, en el mismo emplazamiento. Seria en esta fecha cuando se decidió cambiar su ubicación por la Plaza Jinetes de Alcalá — actualmente Plaza de la Porta de Santa Catalina-. ${ }^{28}$ Dicho cambio estuvo motivado — tal y como explica Antoni Femenia Soler, antiguo jefe de Seguridad Vial de la Jefatura Provincial de Tráfico de las Islas Baleares- por la Feria de Muestras que se montaba cada año en los jardines de sa Feixina. ${ }^{29}$ De aquí que las autoridades optasen por buscar una mejor ubicación. El nuevo emplazamiento del parque fue inaugurado el 20 de enero de 1965, coincidiendo con la festividad del patrono de la ciudad, San Sebastián. ${ }^{30} \mathrm{Al}$ acto asistieron alumnos de diferentes colegios de Palma, representantes del Ayuntamiento, la Policía Municipal y la Jefatura Provincial de Tráfico. La policía se encargó de la gestión del parque y por su pista desfilaron un importante número de niños que realizaron allí sus prácticas de circulación

\footnotetext{
${ }_{28}$ Anónimo, «Noticiario con motivo de la festividad de San Sebastián», Última Hora, 15 de enero de 1965.

${ }^{29}$ Información extraída de la entrevista realizada a Antoni Femenia Soler el día 6 de julio de 2017. Duración: 1:12:04.

30 Anónimo, «Como celebrará nuestra ciudad la fiesta de San Sebastián, su celestial Patrono. Homenaje al personal de Son San Juan. Función religiosa en la Catedral. La Avenida de Don Juan March. Pista Municipal de Tráfico. La Escuela de Son Españolet», Diario de Mallorca, 15 de enero de 1965.
} 
(imagen 4), así como las pruebas clasificatorias para representar al parque en los Campeonatos Nacionales de Parques Infantiles de Tráfico. ${ }^{31}$ Esta competición, en la que se realizaban pruebas individuales y por equipos, fue organizada desde 1965 por la JCT y sirvió para reunir cada año a los niños más talentosos a nivel nacional. ${ }^{32}$ En este sentido, cabe remarcar la ausencia de niñas en estos campeonatos. En su organización también colaboraron distintos patrocinadores - Schweppes, La Casera, Coca-Cola, etcétera-. En la primera edición, celebrada en Madrid en 1965, Mallorca estuvo representada por un total de tres equipos: Palma, Campos y sa Pobla (imagen 5). Los alumnos que asistían iban acompañados por un monitor del parque. En el caso de Palma fue Miguel Bauzá Buades el encargado de acompañarlos durante los primeros campeonatos. Respecto al segundo campeonato, también celebrado en Madrid, cabe destacar que uno de los alumnos de Palma, Juan Bauzá, ganó la competición individual. 33 Junto a él participaron Antonio Bisañez, Juan Socías y Miguel Becerril.

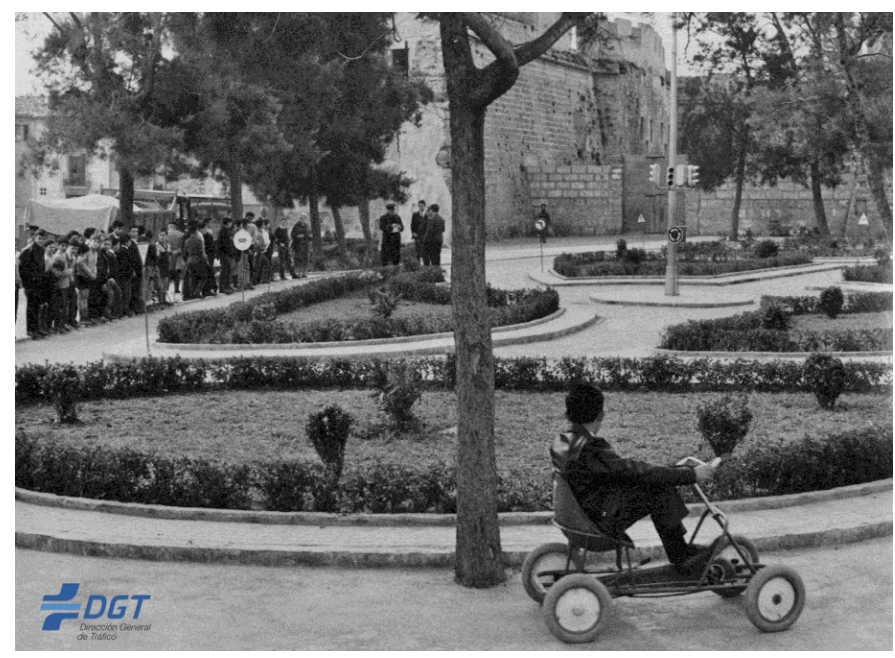

Imagen 4. Prácticas de circulación en el parque de tráfico de Palma, Plaza Jinetes de Alcalá (1965). Imagen cedida por la Jefatura Provincial de Tráfico de las Islas Baleares. Dirección General de Tráfico. Autor: desconocido.

\footnotetext{
31 Juan Cabot, «Inauguración del Parque Infantil de Tráfico», Cort. Revista Mallorquina 488 (febrero, 1965): s.p.

32 Juan Mascarell, «Campeonato nacional de parques infantiles de tráfico», La Vanguardia española, 11 de marzo de 1965.

33 Anónimo, «Juan Bauzá, de Palma, Campeón de Campeones», Baleares, 30 de marzo de 1966.
} 


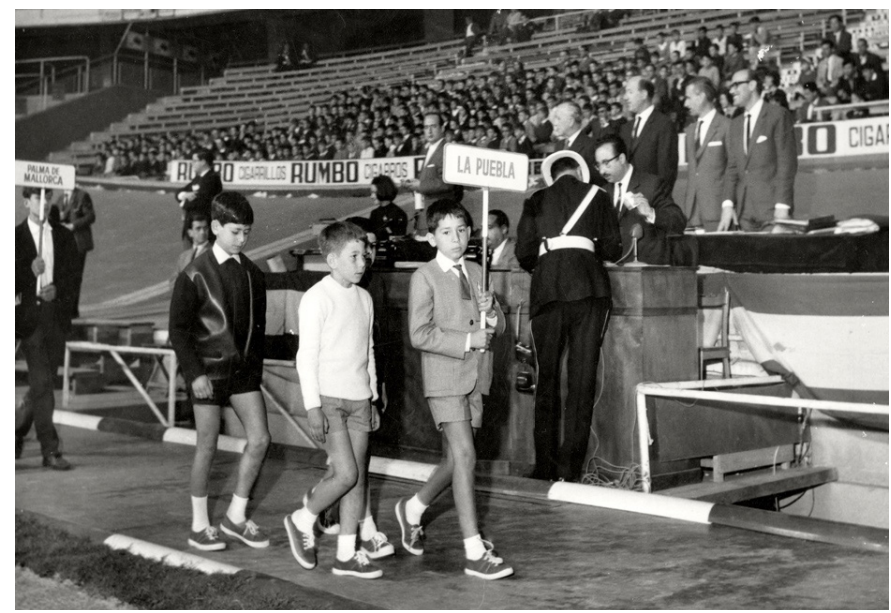

Imagen 5. I Campeonato Nacional de Parques Infantiles de Tráfico, Madrid (1965). Imagen cedida por Joan Llabrés. Autor: desconocido.

Acorde con la Orden de 11 de enero de 1967, el consistorio municipal también aprobó un reglamento que regulaba el funcionamiento del parque de tráfico de Palma. ${ }^{34}$ En él se estipuló que las instalaciones serían utilizadas gratuitamente por niños cuya edad estuviera comprendida entre los seis y catorce años. Se establecieron dos modalidades de enseñanza: a través de la Inspección de Enseñanza Primaria, y la modalidad de concurrencia libre destinada a aquellos niños que voluntariamente querían acudir al parque de tráfico fuera del horario escolar. También se creó una Junta Rectora compuesta por: presidente, director, secretario y monitores. Las diferentes juntas, creadas tanto en Palma como en el resto de parques de la isla, eran el máximo organismo encargado de la gestión y mantenimiento de las instalaciones.

\section{Parque Infantil de Tráfico de Campos (1963)}

El segundo parque construido en Mallorca se inauguró el 19 de mayo de 1963 en el patio de la escuela graduada de "Campos (imagen 6). ${ }^{35}$ Antonio

\footnotetext{
${ }_{34}$ Ayuntamiento de Palma, Reglamento de Parques Infantiles de Tráfico (Palma: Ayuntamiento de Palma, 1968).

35 Un primer trabajo sobre el parque de tráfico creado en Campos es el que presentamos en el XIX Coloquio de Historia de la Educación celebrado en El Escorial en septiembre de 2017. Para mayor información, véase: Gabriel Barceló-Bauzà y Llorenç Gelabert-Gual, «Educación vial en
} 
Nicolau Cerdó, alcalde de la localidad, jefe local del Movimiento y diputado provincial, fue el principal impulsor de su construcción. ${ }^{36}$ El acto de inauguración empezó con diferentes exhibiciones realizadas por los niños de la escuela nacional sobre cómo debía regularizarse el tráfico y continuó con una exhibición gimnástica de los alumnos del colegio Fray Juan Ballester. A la inauguración asistieron diferentes autoridades locales y provinciales que aprovecharon para visitar la exposición sobre circulación que había montada en el salón de actos del grupo escolar. Dicha muestra contaba con trabajos escolares relacionados con la circulación, croquis y maquetas del parque de tráfico, etcétera (imagen 7). Por su parte, la escuela nacional de niñas participó en la exposición con una mantelería en la que había bordadas algunas señales de circulación. El diseño del parque corrió a cargo de Pedro Ponseti, director de la escuela graduada de niños, en colaboración con el jefe provincial de Tráfico, Tomás Sastre. ${ }^{37}$ En el parque de Campos, al igual que sucedía en el caso de Palma, los niños ponían en práctica todas las normas de circulación, desarrollando distintos roles como usuarios de la vía pública (imagen 8).

\footnotetext{
Mallorca durante el franquismo. Memoria e imágenes del primer parque infantil (1963)», en Imágenes, discursos y textos en Historia de la Educación. Retos metodológicos actuales, ed. Sociedad Española de Historia de la Educación (Alcalá de Henares: Servicio de Publicaciones de la Universidad de Alcalá de Henares, 2017), 62-65. También puede consultarse: Anónimo, «Inauguración del Campo Municipal de tráfico en Campos», Diario de Mallorca, 23 de mayo de 1963; Miguel Roig, «Fue inaugurado el Parque Infantil de Tráfico de Campos y una exposición escolar sobre circulación», Baleares, 22 de mayo de 1963; Anónimo, «En Campos del Puerto fue inaugurado un "Parque Infantil de Tráfico"», Cort. Revista Mallorquina 449 (junio, 1963): s.p; Anónimo, "Campos del Puerto. Inauguración del Parque Infantil de Tráfico», Lealtad: revista gráfica balear 92 (junio, 1963): 18.

36 De la implicación del alcalde Antonio Nicolau en la construcción del parque de Campos se da testimonio en diferentes noticias: Miguel Roig, «Parque Infantil de Tráfico», Baleares, 28 de febrero de 1963; Miguel Roig, «El Día Internacional sin Accidentes en Campos», Baleares, 8 de mayo de 1963; Miguel Roig, "Fue inaugurado el Parque Infantil de Tráfico».

37 Pedro Ponseti Olives, «Memoria de las actividades y realizaciones efectuadas por el opositor Pedro Ponseti Olives al frente de la Escuela Nacional Graduada de Niños de Campos del Puerto (Baleares), de su Dirección y Concepto que tiene el opositor de la organización de un Colegio Nacional», abril de 1967, pp. 76-85, sección Educación y Ciencia, caja 32/01461, Archivo General de la Administración (AGA). En esta memoria da testimonio de algunas de las iniciativas que se llevaron a cabo en el parque de tráfico de Campos desde su inauguración en mayo de 1963.
} 


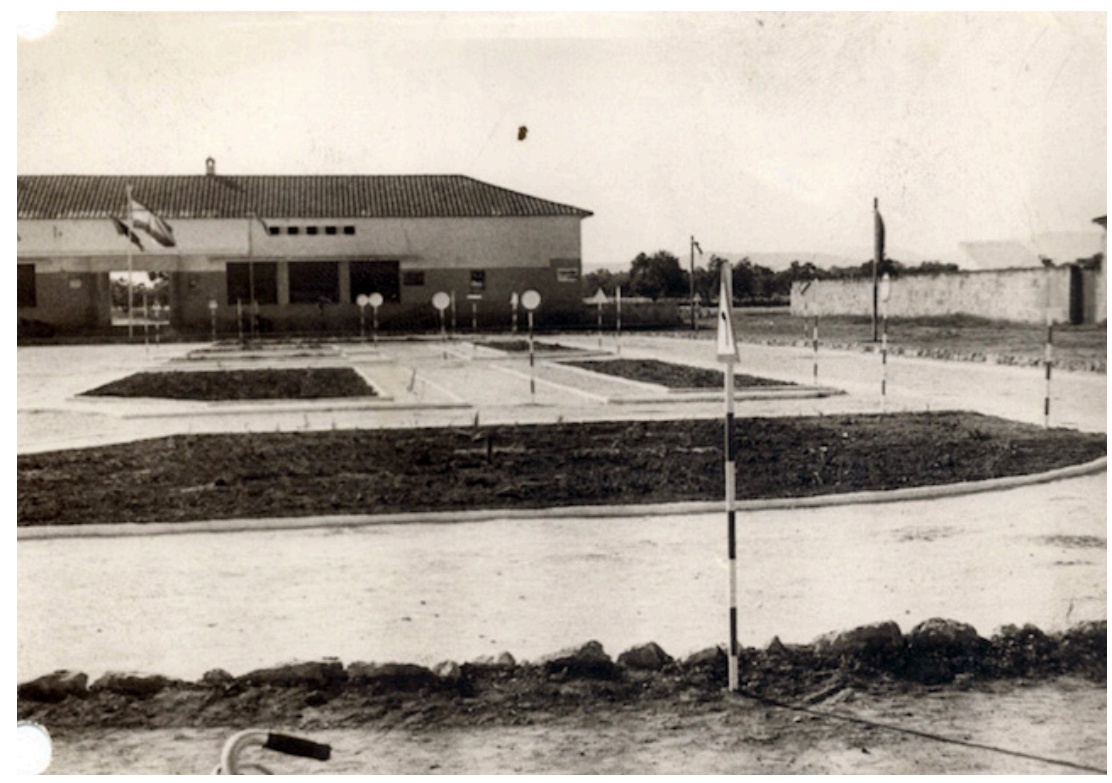

Imagen 6. Parque Infantil de Tráfico de Campos (1963). Imagen cedida por la Jefatura Provincial de Tráfico de las Islas Baleares. Dirección General de Tráfico. Autor: Foto J. Amer.

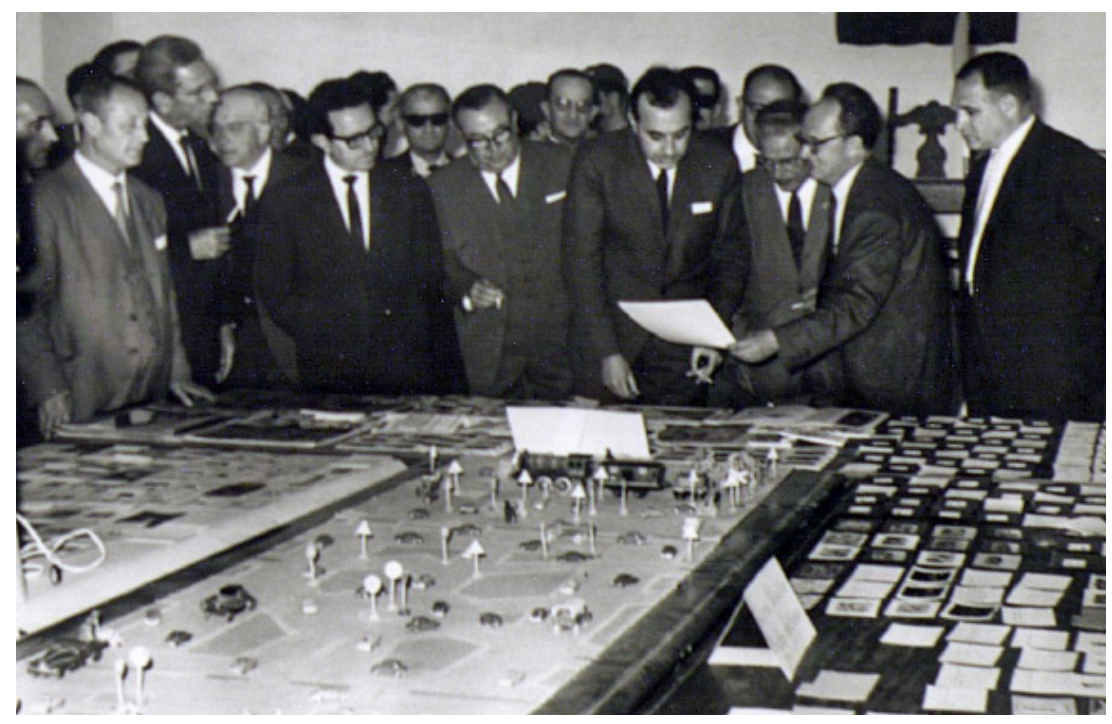

Imagen 7. Exposición sobre circulación, escuela graduada de Campos (1963).

Imagen extraída de la memoria de oposición del maestro Pedro Ponseti

(Archivo General de la Administración. Sección Educación y Ciencia. Caja 32/01461). Autor: desconocido. 


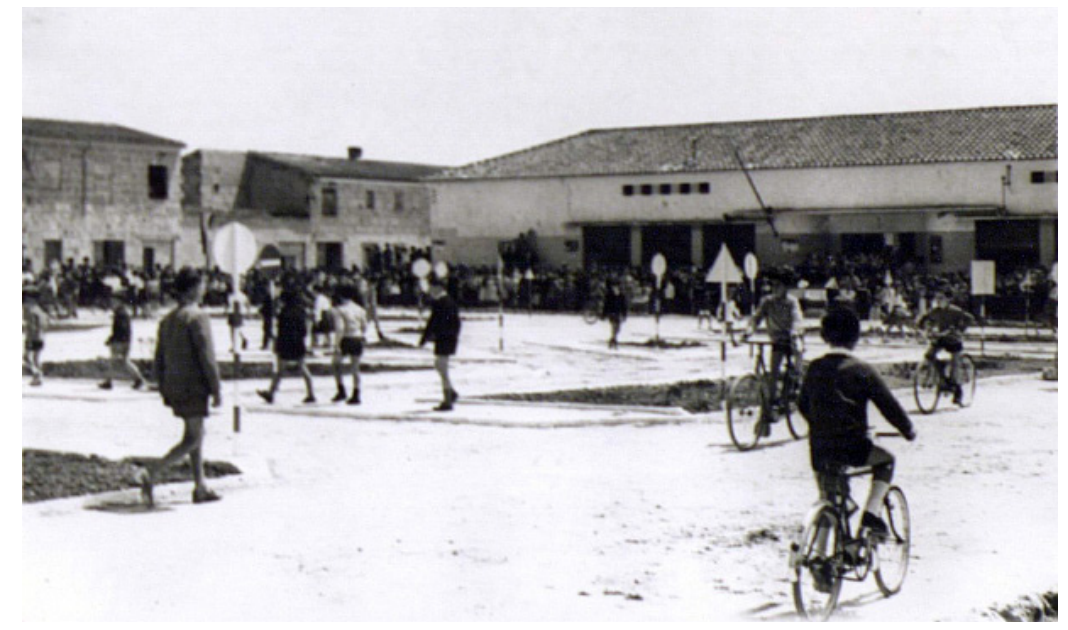

Imagen 8. Prácticas de circulación, parque de tráfico de Campos (1963).

Imagen extraída de la memoria de oposición del maestro Pedro Ponseti (Archivo General de la Administración. Sección Educación y Ciencia. Caja 32/01461). Autor: desconocido.

Todas las actividades prácticas que se realizaban se coordinaban «[...] con las enseñanzas teóricas realizadas en la clase, con ayuda de proyección de diapositivas, fichas del archivo, láminas, etcétera, con un plan y horario previstos». ${ }^{38} \mathrm{Y}$ es que durante los primeros años de existencia del parque la gestión y dirección del mismo corrió a cargo de Pedro Ponseti Olives y del también maestro Jaime Prohens Mas. De hecho, no fue hasta 1966 cuando la Policía Municipal, con Pedro J. Barceló Caldentey como principal responsable, asumió la gestión del parque. El policía Barceló, además de ser el monitor encargado de realizar las enseñanzas teóricas y prácticas, también ostentó la presidencia de la Junta Rectora del parque de Campos y se encargó de acompañar a los representantes del parque en los campeonatos que se celebraban cada año a nivel nacional. ${ }^{39}$

Por otra parte, es preciso remarcar que antes de la inauguración del parque infantil, concretamente en 1962, ya existió una primera experiencia relacionada con la adquisición de habilidades y destrezas en materia de seguridad vial:

\footnotetext{
38 Ponseti, «Memoria de las actividades», 77.

39 Información extraída de la entrevista realizada a Pedro J. Barceló Caldentey el día 1 de junio de 2017. Duración: 1:26:03.
} 
La pujante villa de Campos del Puerto acaba de realizar una curiosa experiencia que es fácil tenga imitadores. Se trata de que los niños de las Escuelas Nacionales dirigieran, por espacio de unas horas, la circulación en aquella villa. La experiencia tiene un alto valor pedagógico y cívico a la vez. En el fondo, un valor educacional. Porque si es verdad que en las Escuelas existe la obligación de enseñar a los alumnos las principales reglas de la circulación, lo más práctico y lo más pedagógico es que los mismos niños tomen parte activa en estas enseñanzas. Y para ello nada mejor que convertirse, por unos momentos, en auténticos «guardias de circulación» con el conocimiento y la responsabilidad que ello entraña. ${ }^{40}$

Esta actividad se puede enmarcar dentro de las múltiples iniciativas que la JCT promovió desde 1960 para celebrar el Día Internacional sin Accidentes. Y es que, aparte de Campos (imagen 9), hubo otros municipios de la isla —Bunyola, ${ }^{41}$ Palma (imagen 10) ${ }^{42}$ o Manacor (imagen 11) _ ${ }^{43}$ que a principios de los sesenta se adhirieron a esta iniciativa. El Día Internacional sin Accidentes era una jornada, dirigida tanto a adultos como a jóvenes, que se celebrada en todo el territorio nacional. ${ }^{44}$ Una de las actividades más características que desarrollaban los niños ese día era la de convertirse en supuestos guardias de circulación —imponían multas a los infractores (imagen 12), advertían a los más reacios a cumplir con el código de circulación, etcétera-. Todo ello con un único objetivo, concienciar a la población de los peligros que traía consigo el aumento del tráfico rodado.

\footnotetext{
40 Anónimo, «Campos es la primera población de la isla que educa a sus muchachos en los problemas del tráfico», Cort. Revista Mallorquina 415-416 (enero-febrero, 1962): s.p. Otra publicación que también informa de la experiencia realizada en Campos es: Anónimo, «Ventanal mallorquín. Campos del Puerto. Al habla con el alcalde», Lealtad: revista gráfica balear 80 (junio, 1962): 45.

${ }^{41}$ Anónimo, «Crónica de Buñola», Diario de Mallorca, 13 de mayo de 1962.

42 Anónimo, «Colaboraron en el Día Internacional sin Accidentes», Diario de Mallorca, 5 de mayo de 1963; Anónimo, «El "Día Internacional sin Accidentes" tuvo amplio eco en toda la ciudad», Baleares, 29 de mayo de 1966.

${ }^{43}$ Anónimo, «El Día Internacional sin Accidentes en Manacor», Diario de Mallorca, 10 de mayo de 1963.

44 Para una mayor información sobre el Día Internacional sin Accidentes puede consultarse: NO-DO número $958 \mathrm{~A}$ (minuto 0:00 a 1:14) de 15 de mayo de 1961. http://www.rtve.es/filmoteca/no-do/not958/1470411/ (consultado el 11-02-2018), y NO-DO número 958 B (minuto 1:20 a 2:53) de 15 de mayo de 1961. http://www.rtve.es/filmoteca/no-do/not-958/1470388/ (consultado el 11-02-2018).
} 


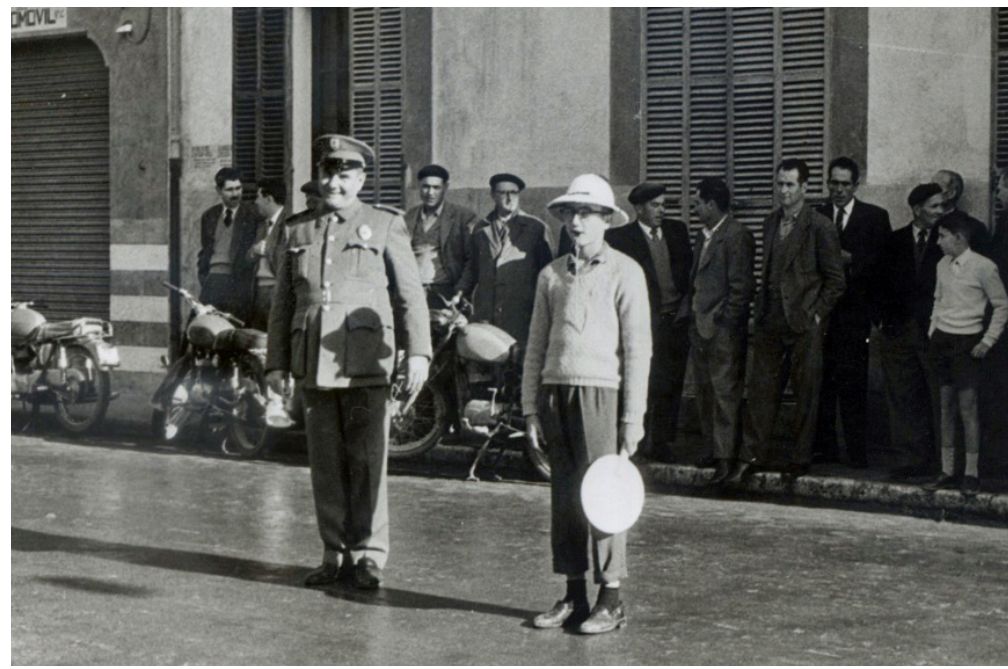

Imagen 9. Día Internacional sin Accidentes, Campos (1962). Imagen cedida por Antoni Femenia. Autor: desconocido.



Imagen 10. Día Internacional sin Accidentes, Palma (1963). Imagen cedida por Antoni Femenia. Autor: desconocido. 


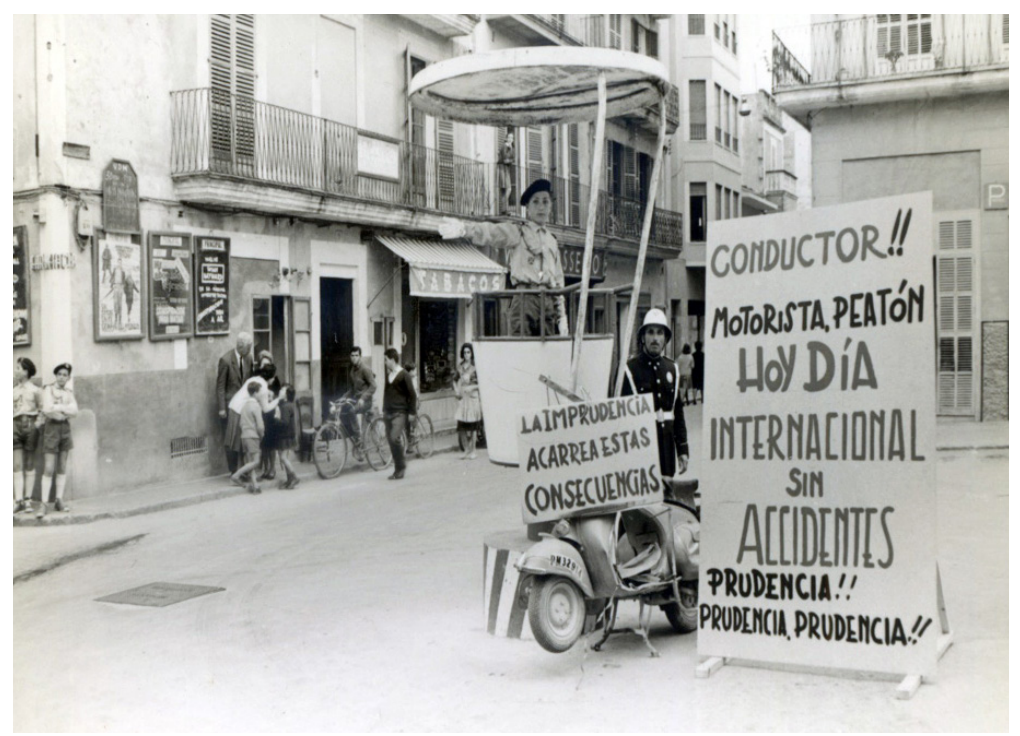

Imagen 11. Día Internacional sin Accidentes, Manacor (1963). Imagen cedida por Antoni Femenia. Autor: desconocido.



Imagen 12. Día Internacional sin Accidentes, Manacor (1964). Imagen cedida por Antoni Femenia. Autor: desconocido. 
Por último, cabe añadir que el parque de Campos también albergó las pruebas locales de selección para representar al municipio en los campeonatos nacionales (imagen 13). ${ }^{45}$ En el caso del primer campeonato, celebrado en 1965, Campos estuvo representado por Emilio Cayuela Guerrero, Antonio Obrador Font, Andrés García Tauler y Luis Ledesma Arellano. ${ }^{46} \mathrm{Al}$ año siguiente, los participantes fueron Nicolás Verdera Huguet, Andrés García Tauler, Pedro Juliá Campos y Mateo Lladonet Moll. ${ }^{47}$

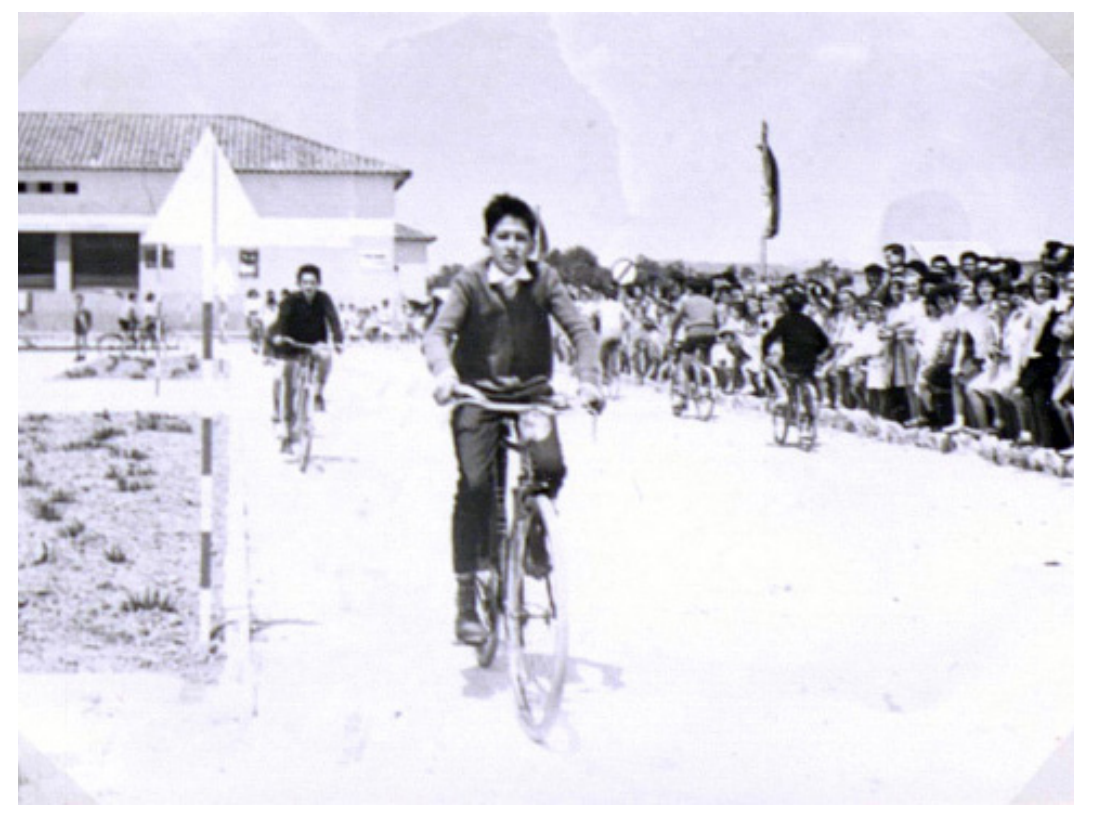

Imagen 13. Campeonato local, Campos (1966). Imagen extraída de la memoria de oposición del maestro Pedro Ponseti (Archivo General de la Administración. Sección Educación y Ciencia. Caja 32/01461). Autor: desconocido.

\footnotetext{
${ }^{45}$ Un primer trabajo sobre la representación del parque de Campos en los Campeonatos Nacionales de Parques Infantiles de Tráfico puede consultarse en Pau Tomàs Ramis, «La representació campanera als tres primers campionats d'Espanya de parcs infantils de trànsit (1965-1967)», en I Jornades Estudis Locals de Campos, ed. Ajuntament de Campos. Mancomunitat Migjorn Mallorca (Campos: Impremta Adrover, 2015), 371-388.

46 Tomàs, «La representació campanera», 381.

${ }_{47}$ Miguel Roig, «Se celebró el Concurso del Parque Infantil de Tráfico, de Campos», Baleares, 4 de marzo de 1966.
} 


\section{Parque Infantil de Tráfico de sa Pobla (1965)}

El parque de tráfico de sa Pobla se inauguró el 26 de febrero de 1965.48 En este caso su construcción se llevó a cabo gracias a la iniciativa de Francisco Gost Amer, conocido empresario de la localidad. El motivo por el que Gost impulsó su creación fue debido a un traumático accidente de tráfico que sufrió años atrás. ${ }^{49}$ Gracias a su donación —un total de cincuenta mil pesetas-y a la colaboración del «Comité Pro Parque Infantil de Tráfico», 50 el Ayuntamiento y la Jefatura Provincial de Tráfico, se pudo instalar el nuevo parque en unos terrenos de titularidad municipal anexos a la escuela graduada. A su inauguración asistieron representantes de la JCT, los alcaldes de sa Pobla, Palma e Inca y el jefe provincial de Tráfico, así como algunos miembros del «Comité Pro Parque Infantil». También cabe resaltar la demostración de prácticas de circulación realizada por parte de alumnos de los centros escolares del municipio. Para ello se sirvieron de sus propias bicicletas y de los cinco karts a pedal que había enviado la JCT. Finalizada la actuación se entregó a los jóvenes un material didáctico para que se familiarizasen con las principales señales y normas de circulación. ${ }^{51}$

Durante los primeros años, concretamente hasta 1976, la gestión del parque estuvo a cargo de los maestros de la escuela nacional Cristóbal Bennasar, Pedro Mascaró, Fernando Contreras y Llorenç Crespí —hecho que también sucedió en el caso del parque de tráfico de Campos con los maestros Pedro Ponseti y Jaime Prohens-. Posteriormente, fue la Policía Municipal, con Bartomeu Alomar Batle al frente, la encargada de gestionar su funcionamiento. ${ }^{52}$

\footnotetext{
48 Anónimo, «Bendición del Parque Infantil de La Puebla», Diario de Mallorca, 27 de febrero de 1965; Anónimo, «Inauguración de un Parque Infantil en La Puebla», Última Hora, 26 de febrero de 1965; Eugenio Triay, «Inauguración del Parque Infantil de Tráfico en La Puebla. Asistieron distinguidas personalidades de la Jefatura Central de Tráfico», Baleares, 27 de febrero de 1965; Antonio Vidal, "Parque Infantil de Tráfico», La Vanguardia española, 27 de febrero de 1965.

49 Juan Payeras, «Más de medio siglo de educación vial en sa Pobla», Diario de Mallorca, 11 de abril de 2017.

${ }^{50} \mathrm{El}$ «Comité Pro Parque Infantil de Tráfico» estuvo encabezado por dos personalidades muy relevantes en la vida cultural del municipio. Nos referimos a Alejandro Cuéllar (secretario del Ayuntamiento) y a Alexandre Ballester (cronista oficial).

51 Eugenio Triay, «Inauguración del Parque Infantil de Tráfico en La Puebla».

${ }_{52}$ Aparte de Bartomeu Alomar, hubo dos policías municipales más que también ayudaron en la gestión del parque de sa Pobla, Francisco Company Pol y Bartomeu Mir Serra.
} 
El parque de sa Pobla, además de servir como espacio para la formación de los escolares en materia de seguridad vial, también acogió las pruebas locales clasificatorias para representar al municipio en los campeonatos que se celebraban a nivel nacional (imagen 14). Cada año entre los meses de marzo y abril se disputaban pruebas de carácter teórico y práctico con el fin de seleccionar a los mejores alumnos. En el caso del segundo campeonato nacional celebrado en 1966 en Madrid, sa Pobla estuvo representada por Antonio Vilches, Bartolomé Mir, Lorenzo Cañellas y Celió Ballester. ${ }^{53} \mathrm{El}$ maestro Fernando Contreras fue el encargado de acompañarlos durante los primeros campeonatos.

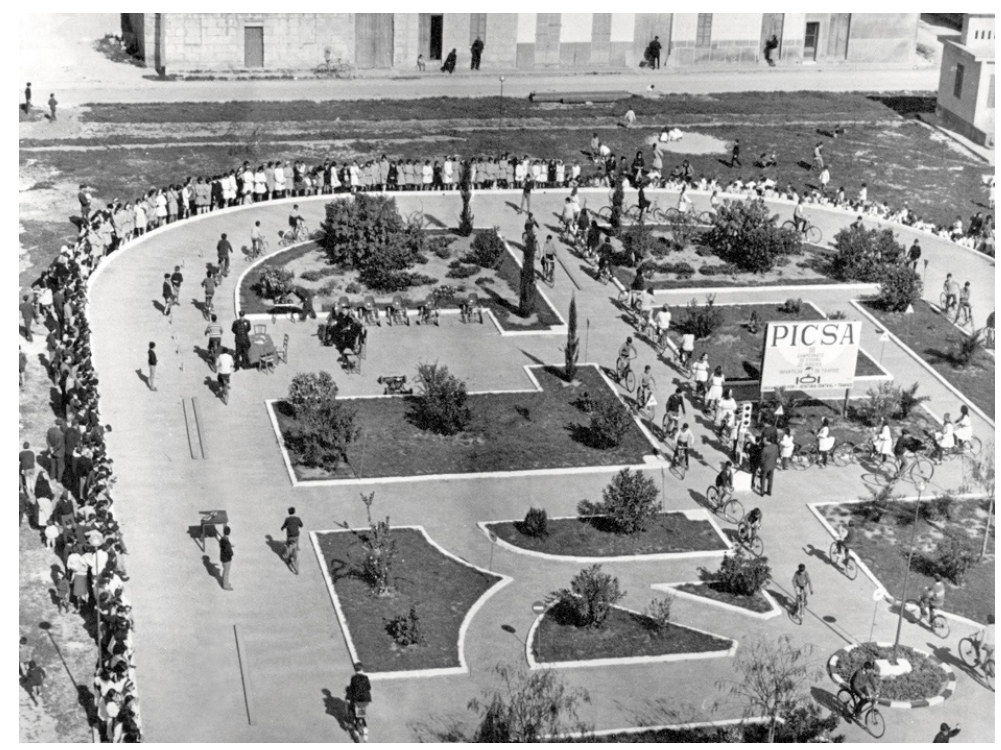

Imagen 14. Campeonato local, sa Pobla (1967). Imagen cedida por Joan Llabrés. Autor: Onofre Pons.

Cabe destacar, finalmente, que en 1975 la competición nacional de parques infantiles de tráfico se celebró en Mallorca. Sa Pobla, Felanitx y Palma, fueron los lugares escogidos para realizar las pruebas. El ganador de la competición por equipos fue sa Pobla, localidad que albergó las pruebas de karts (imagen 15)..$^{54}$

\footnotetext{
53 Tomàs, «La representació campanera», 386.

${ }_{54}$ Para mayor información, véase: Anónimo, «Hoy se inicia el campeonato de España de parques de tráfico infantiles. Felanitx y sa Pobla, escenarios de las primeras pruebas», Diario de Mallorca, 2 de mayo
} 


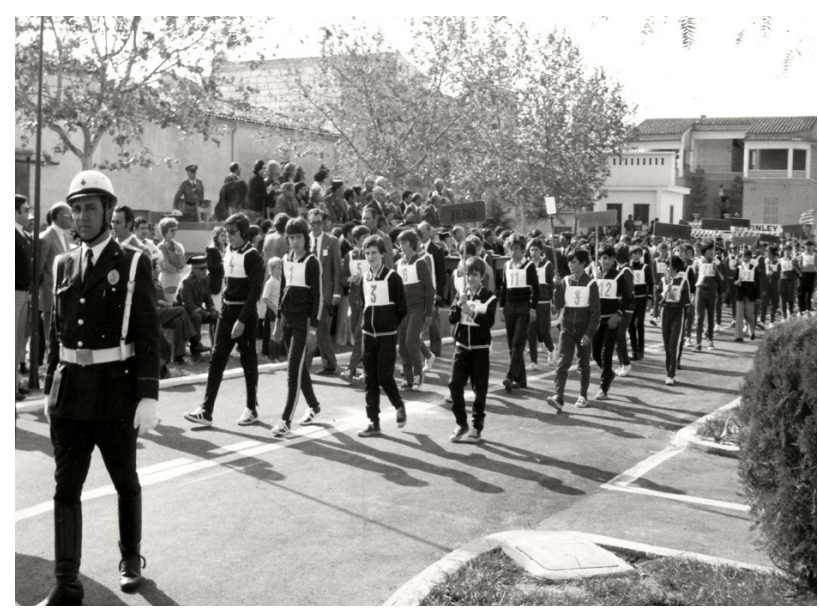

Imagen 15. XI Campeonato Nacional de Parques Infantiles de Tráfico, sa Pobla (1975). Imagen cedida por Joan Llabrés. Autor: desconocido.

\section{Parque Infantil de Tráfico de Felanitx (1969)}

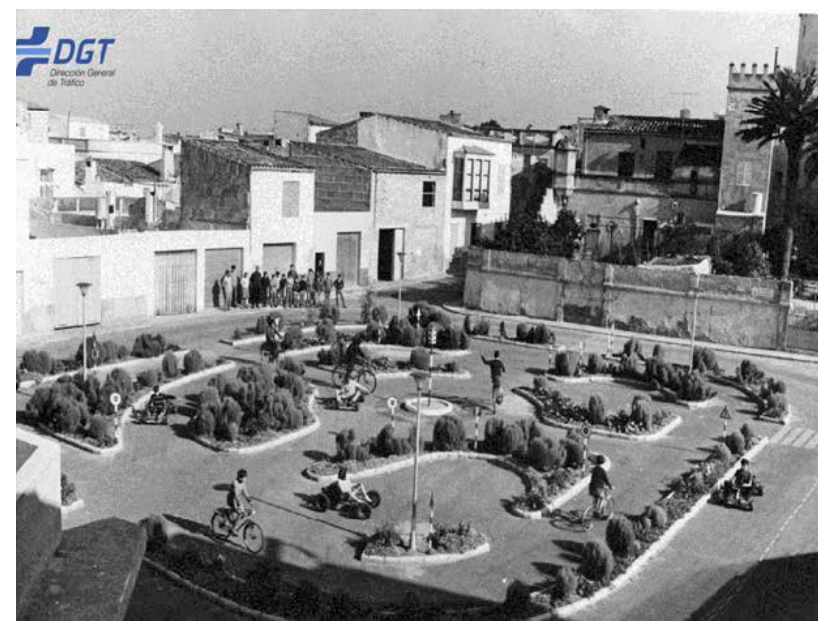

Imagen 16. Parque Infantil de Tráfico de Felanitx (1969). Imagen cedida por la Jefatura Provincial de Tráfico de las Islas Baleares. Dirección General de Tráfico. Autor: desconocido.

de 1975; Miguel Juliá y Juan Payeras, «Luz verde al campeonato de España de parques infantiles de tráfico. El instituto de Felanitx, escenario de las pruebas teóricas. Por la tarde se disputaron las pruebas de "Karts" en sa Pobla», Diario de Mallorca, 3 de mayo de 1975; Anónimo, "XI Campeonatos nacionales de parques infantiles de tráfico. El equipo de sa Pobla, campeón de España», Última Hora, 5 de mayo de 1975; Alexandre Ballester, «Un campionat nacional a sa Pobla», Sa Plaça 125 (junio, 2003): 2-3. Sobre la celebración de este campeonato también puede consultarse: NO-DO número $1.687 \mathrm{~B}$ (minuto 0:00 a 2:01) de 12 de mayo de 1975. http://www.rtve.es/filmoteca/no-do/not-1687/1466876/ (consultado el 11-02-2018). 
El parque de tráfico de Felanitx inició su actividad en el mes de septiembre de 1969.55 Anteriormente, se había aprobado su construcción en la sesión plenaria municipal del 15 de enero de $1968 .{ }^{56}$ La nueva instalación, diseñada por el arquitecto Valentín Sorribas, ${ }^{57}$ se ubicó en la parte central de la plaza Mossèn Cosme Bauçà — antigua plaza de la Sínia-, situada en la intersección de las calles Noria, Darder y Verí (imagen 16). La elección de dicho emplazamiento estuvo motivada por el poco tráfico rodado que existía en la zona. Cabe añadir que a diferencia de los otros parques creados en Mallorca entre 1962 y 1975, éste fue el único que nunca llegó a inaugurarse de forma oficial. ${ }^{58}$ Las obras para su construcción se iniciaron en marzo de 1968 y terminaron en junio de 1969:

Han empezado las obras de acondicionamiento de la plaza Mn. Cosme Bauzá, en donde, como saben nuestros lectores, se va a construir un parque infantil de tráfico. La semana pasada quedó derruido el brocal cubierto de la «Sínia» y en la presente se ha venido trabajando en las aceras y preparación de calzadas. ${ }^{59}$

Hace algunas semanas que quedaron totalmente concluidas las obras del parque infantil de tráfico de la Pza. Mn. Cosme Bauçà, ya que con la instalación del semáforo central ha quedado a punto de inaugurarse. No tenemos noticia de cuándo serán inauguradas oficialmente estas instalaciones, pero suponemos que

\footnotetext{
55 Anónimo, «Felanitx: el Parque Infantil de Tráfico», Baleares, 28 de septiembre de 1969; Anónimo, «El Parque Infantil de Tráfico. Banca March y D. Antonio Fontanet Obrador han donado sendos karts para esta nueva instalación», Felanitx. Semanario de intereses locales 1640 (septiembre, 1969): 1.

56 Anónimo, "Ayuntamiento de Felanitx», Felanitx. Semanario de intereses locales 1556 (febrero, 1968): 2.

57 Valentín Sorribas Subirá, «Ayuntamiento de Felanitx. Proyecto de Parque Infantil de Tráfico en la plaza de la Sínia», noviembre de 1967, pp. 1-8, signatura V-949/2, Arxiu General del Consell de Mallorca (ES AGCM). También pueden consultarse las siguientes noticias de prensa: Anónimo, «Ayuntamiento de Felanitx», Felanitx. Semanario de intereses locales 1538 (septiembre, 1967): 2; Anónimo, "Ayuntamiento de Felanitx», Felanitx. Semanario de intereses locales 1547 (diciembre, 1967): 2.

58 Anónimo, «Fue aplazada la inauguración oficial del Parque Infantil de Tráfico», Felanitx. Semanario de intereses locales 1661 (febrero, 1970): 1.

59 Anónimo, «Información local. Obras municipales», Felanitx. Semanario de intereses locales 1560 (marzo, 1968): 4. Otra noticia que informaba del estado de las obras es: Anónimo, «Información local. Pavimentación de la plaza Mn. Cosme Bauçà», Felanitx. Semanario de intereses locales 1588 (septiembre, 1968): 4.
} 
se esperará una fecha más propicia ya que su funcionamiento queda en cierto modo ligado a las actividades escolares. ${ }^{60}$

Al igual que los parques de Campos y sa Pobla, el de Felanitx pudo iniciar su actividad gracias a la tarea desarrollada por Matías Barceló, maestro nacional y delegado local de juventud. Además de su labor también resultaron cruciales las aportaciones económicas y materiales — karts y discos de señalización- otorgadas por instituciones, entidades bancarias, marcas comerciales y personas ligadas al mundo empresarial. ${ }^{61}$ El trazado del parque estaba compuesto por diferentes vías, entrelazadas las unas con las otras, reguladas por señales y un semáforo central. Además del utillaje referenciado, el parque de Felanitx también contó con farolas para su iluminación y zonas ajardinadas.

Aparte de las prácticas de circulación — realizadas por alumnos de los centros de enseñanza primaria-, el parque también albergó los torneos clasificatorios para representar al municipio en los campeonatos nacionales. Su primera participación tuvo lugar en Barcelona en el año 1970, coincidiendo con la sexta edición de estos campeonatos. ${ }^{62}$ Representaron al parque Miguel Rosselló Manresa, Juan Obrador Obrador, Jaime Suñer Ramón y Miguel Adrover Sastre. Los monitores que les acompañaron fueron Matías Barceló y Cristóbal Rosselló. El equipo quedó en decimoquinto lugar — la mejor clasificación de los equipos de Baleares-. 63

\footnotetext{
${ }^{60}$ Anónimo, «Información local. El Parque Infantil de Tráfico», Felanitx. Semanario de intereses locales 1630 (julio, 1969): 4.

${ }^{61}$ Anónimo, "Ayuntamiento de Felanitx», Felanitx. Semanario de intereses locales 1610 (febrero, 1969): 2; Anónimo, "Ayuntamiento de Felanitx», Felanitx. Semanario de intereses locales 1615 (marzo, 1969): 2; Anónimo, «Ayuntamiento de Felanitx», Felanitx. Semanario de intereses locales 1630 (julio, 1969): 2; Anónimo, «El Parque Infantil de Tráfico. Banca March»; Anónimo, «Un nuevo Kart, donado por el Banco de Crédito Balear, para el Parque Infantil de Tráfico», Felanitx. Semanario de intereses locales 1645 (octubre, 1969): 1; Anónimo, «Dos nuevos karts para el Parque Infantil de Tráfico, donados por Banesto y Caja de Pensiones», Felanitx. Semanario de intereses locales 1651 (diciembre, 1969): 1; Anónimo, "Ayuntamiento de Felanitx», Felanitx. Semanario de intereses locales 1661 (febrero, 1970): 2.

${ }^{62}$ Anónimo, «Información local. Examen de selección para asistir al VI Campeonato Nacional de Parques Infantiles de Tráfico», Felanitx. Semanario de intereses locales 1669 (abril, 1970): 4.

${ }_{63}$ Anónimo, «VI Campeonato Nacional de Parques Infantiles de Tráfico», Felanitx. Semanario de intereses locales 1673 (mayo, 1970): 1.
} 
Posteriormente, participaron en las convocatorias celebradas en Valencia (1971) y Almería (1972). En el caso del campeonato celebrado en 1971 el equipo ocupó la décima posición, de un total de cuarenta y dos equipos participantes. ${ }^{64}$ A todo esto, cabe añadir que uno de sus integrantes, Juan Ferragut Puig, fue preseleccionado para formar parte del equipo nacional que debía participar en el Campeonato Mundial de Parques Infantiles de Tráfico que se celebraba ese mismo año en Lisboa. ${ }^{65}$

\section{Parque Infantil de Tráfico de Manacor (1974)}

El último de los parques creados en Mallorca durante la dictadura franquista fue el de Manacor. Se inauguró el 19 de mayo de 1974 en la plaza Cardenal Pou, situada entre las calles pintor Solana, Hernán Cortés, Pizarro y Pelayo. ${ }^{66}$ Durante el acto, al que asistieron autoridades locales y provinciales, "[...] un grupo de niños de Felanitx, Manacor, La Puebla y Palma hicieron unas exhibiciones con "karts" en el recinto de la pista recién inaugurada».67

Su construcción se había proyectado en 1971, siendo Pedro Galmés el alcalde y Juan Ginard el arquitecto responsable — de la dirección de las obras se encargó el arquitecto municipal Carlos Terrassa- ${ }^{68} \mathrm{La}$ creación del parque se inició en septiembre de 1973 y finalizó el 4 de mayo de 1974. Al igual que el resto de parques existentes en la isla, realizó durante sus años de existencia tareas formativas y de concienciación dirigidas a la formación de los más jóvenes en materia de seguridad vial.

\footnotetext{
${ }^{64}$ Anónimo, «Felanitx en X lugar en el Concurso N. de Parques de Tráfico. Un preseleccionado para el equipo Nacional», Felanitx. Semanario de intereses locales 1725 (mayo, 1971): 1.

${ }_{65}$ Anónimo, «Juan Ferragut Puig preseleccionado para los Campeonatos del Mundo de Parques Infantiles de Tráfico», Felanitx. Semanario de intereses locales 1726 (mayo, 1971): 1.

${ }^{66}$ Un primer estudio realizado sobre el parque de Manacor puede consultarse en: Antoni Sureda Vicens, «La placeta dels karts. De l'orgull a l'oblit», Perlas y Cuevas. Revista de Manacor 1319 (octubre, 2013): 929-936.

67 Anónimo, «Manacor en fiestas. Diversas inauguraciones oficiales fueron presididas por el gobernador civil y jefe provincial del Movimiento», Baleares, 21 de mayo de 1974, 11. De la inauguración del parque de tráfico de Manacor también informó la revista local Perlas y Cuevas. Para mayor información véase: Anónimo, «Parque Infantil de Tráfico», Perlas y Cuevas. Revista de Manacor 330 (mayo, 1974).

68 Una entrevista en la que el alcalde de Manacor destaca la importancia que tiene para la ciudad la inauguración del parque de tráfico puede consultarse en: Pepe Pardo, «Extra Manacor. Pedro Galmés Riera. "Todavía nos queda mucho por hacer"», Diario de Mallorca, 19 de mayo de 1974.
} 
Respecto al trazado, cabe mencionar que su diseño fue considerado el más vanguardista de los parques que se crearon en Mallorca entre 1962 y 1975.69 De forma cuadrada y con un puente que atravesaba la pista, fue una obra muy novedosa a nivel arquitectónico. Además del trazado había bancos, zonas ajardinadas y un pequeño quiosco. Respecto al reglamento que reguló el funcionamiento del parque éste no se aprobó hasta el 4 de julio de $1985 .{ }^{70}$ Redactado por el cabo de la Policía Municipal y monitor del parque, Juan Truyols Pascual, estableció la creación de una Junta Rectora — compuesta por un presidente, un secretario, un director y un monitor- y otorgó al consistorio municipal la responsabilidad en materia de conservación y explotación de las pistas del parque. ${ }^{71}$

En el parque de Manacor también se celebraban las pruebas clasificatorias para participar en los campeonatos nacionales. Para agilizar su realización cada colegio escogía a aquellos alumnos que demostraban mejores aptitudes. Primero se realizaban las pruebas teóricas, en las que se contestaba a un cuestionario de unas treinta preguntas relacionadas con el código de circulación. A continuación, se desarrollaban las pruebas de circulación en el parque. Tal como explica Antoni Sureda, actual inspector jefe de la Policía Local de Manacor, el recorrido debía realizarse acorde con la normativa de tráfico, pudiéndose cometer faltas graves y leves, con la consiguiente pérdida de puntos. ${ }^{72}$ También se hacían las pruebas de habilidad con bicicleta. Éstas consistían en: pasar entre hileras de conos (imagen 17), realizar ejercicios de eslalon, subir por una rampa, etc.

\footnotetext{
${ }^{69}$ Sureda Vicens, «La placeta dels karts», 930.

70 «Ayuntamiento de Manacor. Reglamento Parque Infantil de Tráfico», Boletín Oficial de Baleares (BOB) no. 18.586 (23 de julio de 1985): 4-5.

71 Sureda Vicens, «La placeta dels karts», 935-936.

72 Sureda Vicens, «La placeta dels karts», 930.
} 


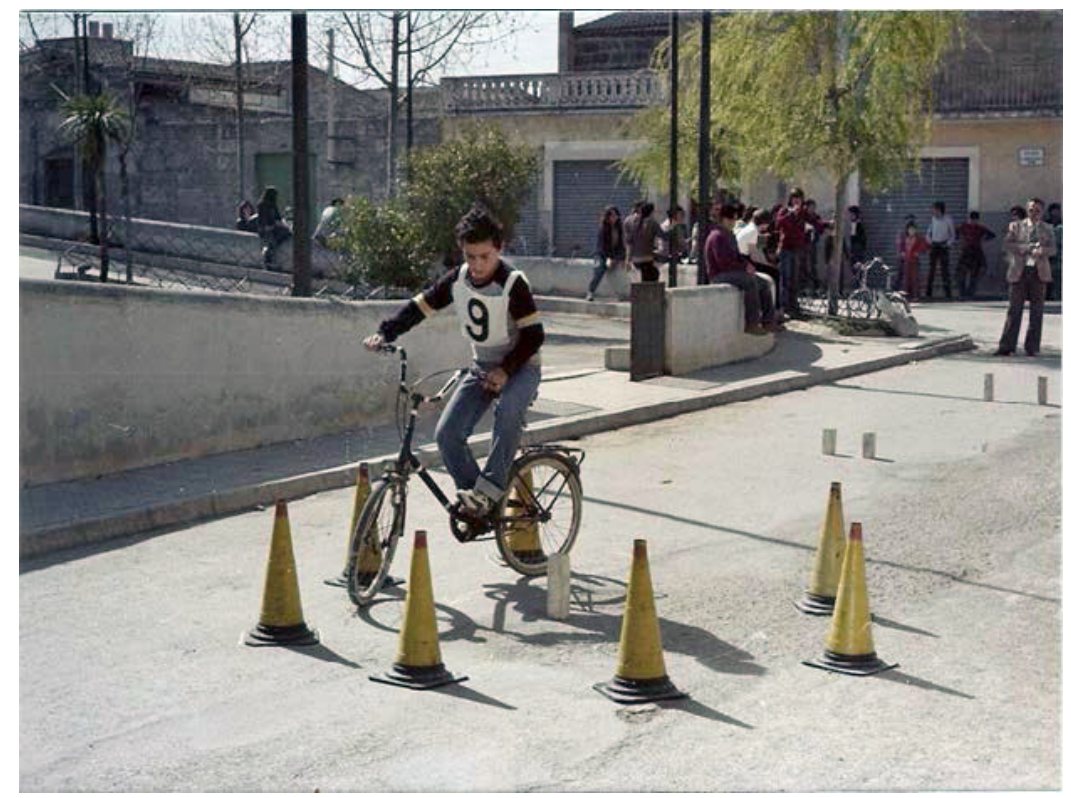

Imagen 17. Campeonato local, Manacor (1975). Imagen cedida por Antoni Sureda. Autor: desconocido.

En cuanto a su actividad en los Campeonatos Nacionales de Parques Infantiles de Tráfico, cabe mencionar que el equipo de Manacor asistió por primera vez en 1975, precisamente el año en que las pruebas se celebraron en Mallorca. Lorenzo Febrer Suñer, Sebastián Galmés Sureda, Antonio Tauler Febrer y José Antonio García Cifo fueron los primeros encargados de representar al parque, quedando el equipo en séptima posición. En 1976 el campeonato se celebró en León y el equipo de Manacor ocupó el octavo lugar. ${ }^{73}$ En el año 1979 uno de los representantes del parque, Mateo Estrany Pascual, fue seleccionado para formar parte del equipo que representaba a España en el XVII Campeonato Mundial de Parques Infantiles de Tráfico que se celebraba en Madrid. De los catorce países que estuvieron presentes, el equipo español ocupó la primera posición seguido de Francia y Portugal. Mateo Pascual, por su parte,

${ }_{73}$ Un interesante reportaje sobre la representación de Manacor en los Campeonatos Nacionales de Parques Infantiles de Tráfico entre 1975 y 1983 puede consultarse en: Anónimo, «Campeonatos infantiles de Tráfico. La representación manacorense ha sido brillante», Baleares, 8 de abril de 1983. 
quedó subcampeón mundial a nivel individual. La efeméride no pasó desapercibida en su ciudad natal. ${ }^{74}$

En relación con las competiciones de parques de tráfico en Baleares cabe mencionar, finalmente, la celebración de campeonatos provinciales. Si bien en los años sesenta y setenta todos los parques de Mallorca mantuvieron una representación constante en las competiciones celebradas a nivel nacional — cada parque seleccionaba a sus representantes-, observamos cómo, a partir de la década de los ochenta, el elevado número de éstos obliga a hacer una preselección a nivel provincial. Es por eso que a partir de 1981 encontramos la celebración de este tipo de competiciones que servían para seleccionar a los dos mejores equipos de Baleares. El primer campeonato se realizó en 1981 en Campos (imagen 18). Le siguieron los de Palma (1982) y Manacor (1983). ${ }^{75}$

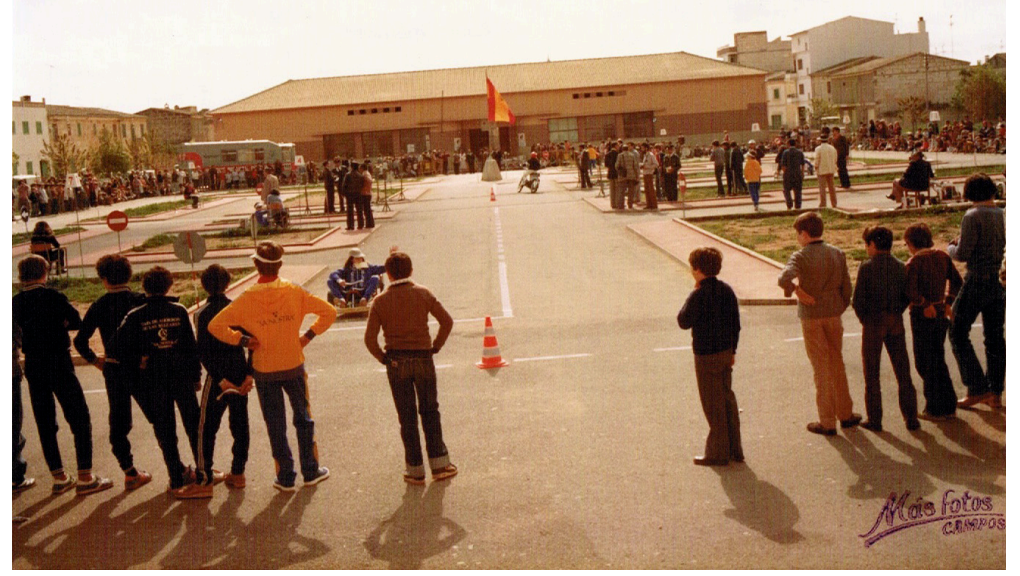

Imagen 18. I Campeonato Provincial de Parques Infantiles de Tráfico de Baleares, Campos (1981). Imagen cedida por Pedro J. Barceló. Autor: Más fotos Campos.

\footnotetext{
${ }^{74}$ Para mayor información, véase: Perlas y Cuevas. Revista de Manacor 460 (junio, 1979).

${ }^{75}$ En el caso del celebrado en Manacor, tomaron parte en la competición los equipos de Mahón, Palma, Manacor, Felanitx, Ciudadela, Campos y sa Pobla. Resultó vencedor el equipo local y Campos quedó en segunda posición. Para mayor información, véase: Anónimo, «El equipo de Manacor, ganó el Campeonato Infantil de Tráfico de Baleares», El lunes, 18 de abril de 1983; Anónimo, «Campeonato infantil de tráfico: Manacor, campeón», Baleares, 17 de abril de 1983.
} 


\section{RECAPITULACIÓN Y CONSIDERACIONES FINALES}

En un contexto de expansión de los vehículos motorizados en España, acompañado de una creciente siniestralidad, las instituciones competentes en los ámbitos de seguridad y educación se vieron en la necesidad de adoptar medidas de concienciación y fomento de un comportamiento cívico en la vía pública. Estas pautas de conducta iban dirigidas a todos los agentes implicados en el tráfico urbano, desde los conductores de cualquier tipo de vehículo, motorizado o no, hasta peatones y guardias de tráfico. Los parques infantiles de tráfico se erigieron como una de las herramientas didácticas con mayor aceptación y difusión a lo largo del territorio nacional.

En el ámbito de la seguridad se adoptaron medidas exclusivamente dirigidas a la disminución de las elevadas tasas de mortalidad en accidentes de tráfico, destacando campañas concretas de concienciación como el Día Internacional sin Accidentes, la creación del cuerpo de profesores de autoescuela o ciclos de conferencias sobre tráfico impulsados desde las distintas jefaturas provinciales. En cuanto al ámbito educativo, objeto de análisis en el presente estudio, se establecieron las bases para la implementación de la educación vial en la escuela a través de nuevas normativas que conjugaban nociones teóricas con prácticas reales. Los parques de tráfico fueron los espacios donde se desarrollaban actividades prácticas dirigidas a los alumnos, pudiendo asumir los diferentes roles de usuarios de la vía pública — peatones, conductores de vehículos, guardias de circulación, etcétera- Si bien su implementación no se dio de forma generalizada en todo el territorio nacional, asentó, en cambio, las bases de futuras acciones formativas relacionadas con el ámbito de la seguridad vial. Fue, además, un ejemplo de introducción en la escuela de contenidos curriculares con una mayor carga cívica y no tanto ideológica.

Si bien a lo largo de la geografía española los parques infantiles de tráfico tuvieron una notable aceptación, es destacable el número de parques creados en un territorio de pequeñas dimensiones como es el caso de Mallorca. Distribuidos entre Palma, la capital, y otras localidades de la isla, se crearon un total de cinco parques entre los años 1962 y 1975. La prensa del momento se hizo eco de las actividades que se desarrollaban en estos parques. Las imágenes icónicas de niños conduciendo vehículos, actuando como peatones o guardias de circulación, sirvió para llamar la atención de una sociedad cada vez más sensibilizada con la siniestralidad en la vía pública. 
En la mayoría de los casos, la creación de estos parques dependía de iniciativas municipales que contaban con la colaboración de la Jefatura Provincial de Tráfico de Baleares y la JCT. En sus inicios, algunos de los parques fueron gestionados tanto por maestros sensibilizados con esta problemática —Campos, sa Pobla y Felanitx—, como por policías municipales. Respecto a su ubicación, debe destacarse que algunos de ellos se construyeron muy cerca, o bien anexos, a los centros escolares. Este hecho, sin duda, facilitó que las actividades se pudieran desarrollar con un mayor número de alumnos y una mejor seguridad. Cabe remarcar que a partir de mediados de los setenta, al menos en el caso de Mallorca, la figura del maestro responsable del parque desapareció. Fue entonces cuando la policía municipal de cada localidad asumió la tutela y gestión de este tipo de instalaciones.

A modo de conclusión, puede afirmarse que los parques infantiles de tráfico se erigieron como una de las iniciativas con mayor repercusión en materia de educación vial. La introducción de esta nueva disciplina en la escuela, si bien no se dio de forma generalizada a lo largo de todo el territorio nacional, aportó nuevos contenidos curriculares más enfocados a la educación en valores. Ésta y otras aportaciones, desarrolladas durante los últimos años del franquismo, contribuyeron, en mayor o menor medida, a establecer las bases de una escuela mucho más abierta y adaptada a los nuevos tiempos.

\section{Nota sobre los autores}

Gabriel Barceló-Bauzà es doctor en Educación por la Universidad de las Islas Baleares (UIB), es profesor ayudante del Departamento de Pedagogía y Didácticas Específicas y miembro del Grupo de Estudios de Historia de la Educación (IRIE/UIB). Su tarea investigadora se ha centrado en la historia de la educación contemporánea, prestando especial atención al estudio de la práctica y cultura escolar de los primeros años de franquismo. También ha trabajado en el uso de la fotografía como fuente para la historia de la educación. Destacan sus artículos en revistas como História da Educação, Encounters in Theory and History of Education, Revista de Educación o History of Education \& Children's Literature. Además de sus tareas docentes e investigadoras también colabora, en calidad de asistente de edición, en la revista Foro de Educación. 
Llorenç Gelabert-Gual, maestro, licenciado en Pedagogía del Lenguaje Musical y postgraduado en Dirección Coral por la Universidad Ramon Llull de Barcelona, es también doctor en Investigación e Innovación en Educación por la Universidad de las Islas Baleares (2012). Su tesis doctoral analizó la corriente musical y pedagógica que emergió en Mallorca en la década de los setenta del siglo pasado a partir del legado del pedagogo y compositor mallorquín Baltasar Bibiloni. Ha publicado artículos en revistas como Educació i Historia, Música y Educación, Foro de Educación, Historia de la Educación, Dedica, Revista de Educação e Humanidades o Anuario Musical, entre otras. En la vertiente musical cuenta con formación en dirección coral y orquestal, piano, saxofón, composición y armonía moderna. Es director musical del Coro de Calvià y fundador y director de Art Vocal Ensemble, agrupación coral e instrumental con la que lleva a cabo una intensa actividad de divulgación y recuperación de nuevos repertorios.

\section{REFERENCIAS}

Ayuntamiento de Palma. Reglamento de Parques Infantiles de Tráfico. Palma: Ayuntamiento de Palma, 1968.

Barceló-Bauzà, Gabriel y Llorenç Gelabert-Gual. «Educación vial en Mallorca durante el franquismo. Memoria e imágenes del primer parque infantil (1963)». En Imágenes, discursos y textos en Historia de la Educación. Retos metodológicos actuales, editado por la Sociedad Española de Historia de la Educación (SEDHE), 62-65. Alcalá de Henares: Servicio de Publicaciones de la Universidad de Alcalá de Henares, 2017.

Coromina Doisy, Javier. Cincuentenario de la DGT: 1959-2009. Madrid: Dirección General de Tráfico. Ministerio del Interior, 2009.

Gorrias Durán, Antoni, Miquel Ramis Serra y Arnau Tugores Ramis. 150 anys de la Policia Municipal: 1852-2002. Palma: Ayuntamiento de Palma, 2002.

Manso Pérez, Violeta. «La educación vial en España. Aspectos históricos-comparados y proyección social». PhD diss., Universidad de Salamanca, 1993.

Manso Pérez, Violeta y Manuel Castaño Pardo. Educación para la seguridad vial. Madrid: Grupo Anaya, 1995.

Manso Pérez, Violeta. «Educación Vial para la Educación Secundaria Obligatoria». En Innovar en las aulas. Modelos y experiencias de innovación educativa en el Máster de Profesorado de Educación Secundaria, Bachillerato, Formación Profesional y Enseñanza de Idioma, editado por Carmen López Esteban, 139156. Salamanca: Ediciones Universidad de Salamanca, 2018. 
Murga Menoyo, María Ángeles. «La movilidad sostenible: un objetivo de la educación vial en el contexto europeo». En Educación vial, seguridad vial, editado por Carmen Jiménez Fernández, 65-91. Barcelona: Editorial Davinci, 2010.

Ocio Simó, Eugenio. «La Educación vial en España: marco histórico legal». En Educación vial, seguridad vial, editado por Carmen Jiménez Fernández, 143161. Barcelona: Editorial Davinci, 2010.

Sureda Vicens, Antoni. «La placeta dels karts. De l'orgull a l'oblit». Perlas y Cuevas. Revista de Manacor 1319 (2013): 929-936.

Tomàs Ramis, Pau. «La representació campanera als tres primers campionats d'Espanya de parcs infantils de trànsit (1965-1967)». En I Jornades Estudis Locals de Campos, editado por Ajuntament de Campos y Mancomunitat Migjorn Mallorca, 371-388. Campos: Impremta Adrover, 2015.

Trillo Miravalles, María Paz. «Evolución legislativa de la educación vial en España: nuevos retos para educadores e instituciones». Ensaio: Avaliação 22, no. 82 (2014): 131-148.

Zabalza Beraza, Miguel Ángel. «La educación vial en el marco de una formación por competencias». En Educación vial, seguridad vial, editado por Carmen Jiménez Fernández, 162-184. Barcelona: Editorial Davinci, 2010. 